\title{
Bromeliaceae endémicas del Perú
}

\section{Blanca León ${ }^{1,2}$, Abundio Sagástegui ${ }^{3}$, Isidoro Sánchez ${ }^{4}$ y Mario Zapata ${ }^{3}$}

${ }^{1}$ Museo de Historia Natural, Av. Arenales 1256, Aptdo. 14-0434, Lima 14, Perú

2 Plant Resources Center, University of Texas at Austin, Austin TX 78712 EE.UU.

blanca.leon@mail.utexas.edu ${ }^{3}$ Herbario, Universidad Particular Antenor Orrego, Trujillo, Perú.

asagasteguia@upao.edu.pe mazacruz@hotmail.com

${ }^{4}$ Herbario, Universidad Nacional de Cajamarca, Aptdo. 55, Cajamarca, Perú. svisidoro@yahoo.com

\section{Resumen}

La familia Bromeliaceae es reconocida en el Perú por presentar 19 géneros y alrededor de 450 especies (Brako \& Zarucchi, 1993; Ulloa Ulloa et al., 2004), todas hierbas, epífitas o terrestres. En este trabajo reconocemos 223 endemismos en 13 géneros. Se asignó las categorías de amenaza de la UICN a 161 taxones. Tres géneros, Tillandsia, Puya y Pitcairnia, son los que incluyen la mayoría de los endemismos en la familia. Estos taxones endémicos ocupan la mayoría de las regiones ecológicas, desde Bosques Pluviales Montanos, Bosques Húmedos Amazónicos en el lado oriental del país, hasta las regiones Mesoandina, de la Puna Seca y Húmeda y Altoandina en el lado occidental, entre los 100 y $4700 \mathrm{~m}$ de altitud. Aproximadamente la mitad de los endemismos es conocido solamente de una localidad, reflejando, en parte, la escasa herborización de los ambientes donde esta familia es diversa y por otro la falta de especialista (-s) en el país. Veintiún de estas especies se encuentran representadas en áreas naturales protegidas.

Palabras claves: Bromeliaceae, Perú, endemismo, plantas endémicas.

\section{Abstract}

The Bromeliaceae are recognized in Peru with 19 genera and approximately 450 species (Brako \& Zarucchi, 1993; Ulloa Ulloa et al., 2004), all epiphytic or terrestrial herbs. Here we recognize 223 endemic taxa in 13 genera. We assigned IUCN threat categories to 161 taxa. Three genera, Pitcairnia, Puya and Tillandsia, encompass the majority of Peruvian endemics in this family. The endemic taxa are found in a wide range of ecological regions, from Pluvial Montane Forest to Lowland Amazonian Forest on the eastern side of the country to the Mesoandean, and Dry and Humid Puna on the western side, between 100 and $4700 \mathrm{~m}$ elevation. Approximately half of the endemic species are known from a single locality, reflecting insufficient exploration of the regions where the family is diverse, and the lack of a specialist in the country. Twenty-one species endemic to Peru have been registered to date in the country's protected areas network.

Keywords: Bromeliaceae, bromeliads, Peru, endemism, endemic plants.

\section{Aechmea arenaria (Ule) L.B. Sm. \& M.A. Spencer VU, Blab(iii)}

Publicación: Phytologia 72(2): 96. 1992.

Colección tipo: E.H.G. Ule 6335

Hemarios: B, MG.

Nombre común: Achupilla.

Registro departamental: LO, MD, SM.

Regiones Ecológicas: BHA; $120-300 \mathrm{~m}$.

SINAN PE: Sin registro.

Herbarios peruanos: USM (1).

Observaciones: Hierba epífita, conocida de localidades aisladas en la Amazonía peruana, en las cuencas del Mayo, Huallaga y Alto Madre de D ios. Podría estar representada en los Parques Nacionales Cordillera Azul y Bahuaja-Sonene.

\section{Aechmea brachystachys (Harms) L.B.Sm.\& M.A. Spencer CR, Blab(iii) \\ Publicación: Phytologia 72(2): 96. 1992. \\ Colección tipo: G. Tessmann 4645 \\ Herbarios: B. \\ Nombre común: D esconocido. \\ Registro departamental: AM. \\ Regiones Ecológicas: BHA; $160 \mathrm{~m}$. \\ SINAN PE: Sin registro. \\ Hemarios peruanos: Ninguno.}

Observaciones: Hierba, probablemente, epífita, conocida solamente de la colección tipo, proveniente de la cuenca del Santiago. Esta especie fue reconocida para Loreto, pero se corrige aquí su distribución. Podría estar representada en la Zona Reservada Santiago-Comaina.

\section{Aechmea confusa H. Luther} DD

Publicación: Selbyana 19: 224. 1998.

Colección tipo: L. Moore A-120

Herbarios: US.

Nombre común: D esconocido.

Registro departamental: LO.

Regiones Ecológicas: BHA; $100 \mathrm{~m}$.

SINANPE: Sin registro.

Herbarios peruanos: Ninguno.

Observaciones: Reconocida en Brako \& Zarucchi (1993) en el género $\mathrm{G}$ reigia. Conocida sólo del ejemplar tipo, una planta cultivada recolectada en Loreto, pero de la que no hay datos sobre su hábitat y la localidad de esta especie.

\section{Aechmea femuginea L.B. Sm. EN, B 1ab(iii)}

Publicación: Contr. Gray Herb. 98: 5, t. 1, f. $1-3.1932$.

Colección tipo: E.P. Killip \& A.C. Smith 25815

Herbarios: NY, US.

Nombre común: D esconocido.

Registro departamental: PA, SM.

Regiones Ecológicas: BMHM, BMHP; 650- $1900 \mathrm{~m}$.

SINANPE: BPSMSC

Herbarios peruanos: Ninguno.

Nota del Editor: En la versión on line de este artículo han sido omitidos los mapas del Perú que ilustraban el Registro departamental. Para ubicar las abreviaturas de los departamentos vea al final del artículo. 
Observaciones: Hierba terrestre, conocida de tres localidades, en la vertiente oriental sobre un área superior a los $500 \mathrm{~km}^{2}$. Las dos últimas colecciones fueron realizadas a inicios de los 1980. Una de las poblaciones se halla en el Bosque de Protección San Matías-San Carlos, por lo que podría estar representada en el Parque Nacional Yanachaga-Chemillén. Los bosques montanos, en la altitud conocida para esta especie, están afectados por la deforestación.

\section{Aechmea paniculata Ruiz \& Pav.}

\section{CR, Bla}

Publicación: Syst. Veg. Fl. Peruv. Chil. 83, f. 80. 1798.

Colección tipo: H. Ruiz \& J. Pavón s.n.

Henbarios: G, MA.

Nombre común: D esconocido.

Registro departamental: HU.

Regiones Ecológicas: BMHP; altitud desconocida.

SINANPE: Sin registro.

Hemarios peruanos: Ninguno.

Observaciones: Hierba epífita, probablemente, de los bosques húmedos premontanos de Pasco. Podría estar representada en el Parque Nacional Yanachaga-Chemillén. A parentementeno havuelto a ser recolectada desde el siglo XIX.

\section{Aechmea vasquezii $\mathrm{H}$. Luther}

\section{EN, Bla}

Publicación: Selbyana 21(1, 2): 129. 2000. Colección tipo: R. Vásquez et al. 22094

Herbarios: MO.

Nombre común: D esconocido.

Registro departamental: AM.

Regiones Ecológicas: BHA; $289 \mathrm{~m}$.

SINAN PE: ZRSC

Herbarios peruanos: Ninguno.

Observaciones: Hierba epífita, conocida sólo de la localidad tipo, en la cuenca del Cenepa, parte de la Zona Reservada Santiago-Comaina.

\section{Billbergia formosa Ule}

\section{EN, Bla}

Publicación: Verh. Bot. Vereins Prov. Brandenburg 48: 138. 1907.

Colección tipo: E.H.G. Ule 60-P

Herbarios: $B$.

Nombre común: D esconocido.

Registro departamental: LO.

Regiones Ecológicas: BHA; $115 \mathrm{~m}$.

SINAN PE: RNAM

Herbarios peruanos: Ninguno.

Observaciones: Hierba epífita, conocida, al parecer, sólo de dos localidades, en los alrededores de Iquitos. Una población ha sido hallada en la Reserva Nacional Allpahuayo-Mishana.

\section{Billbergia incarnata (Ruiz \& Pav.) Schult.f.}

$$
\text { EN, Bla }
$$

Publicación: Syst. Veg. 7(2): 1261. 1830. Colección tipo: H. Ruiz \& J. Pavón 5/ 27 Henbarios: MA.

Nombre común: D esconocido.

Registro departamental: HU, LO, PA, SM. Regiones Ecológicas: BMHP; 800-900 m. SINAN PE: Sin registro.

Henbarios peruanos: USM (2).
Observaciones: Hierba epífita, conocida de las cuencas del Pozuzo y del Huallaga. La localidad original está ubicada al norte del Parque Nacional Yanachaga-Chemillén y es posible que esté representada allí. Una colección de 1973, representa el segundo registro de esta especie.

\section{Billbergia tessmannii Harms}

$$
\text { NT, Bla }
$$

Publicación: Notizbl. Bot. Gart. BerlinDahlem 10: 177-178. 1927.

Colección tipo: G. Tessmann 5318

Herbarios: B.

Nombre común: D esconocido.

Registro departamental: AM, LO, UC.

Regiones Ecológicas: BHA; $100-600 \mathrm{~m}$.

SINAN PE: Sin registro.

Herbanios penuanos: AMAZ (2), USM (2).

Observaciones: Hierba epífita conocida de varias localidades, en el nor-oriente del país, ubicadas en las cuencas del Cenepa, Utcubamba y Amazonas. Habita bosques no mayores de $20 \mathrm{~m}$ de alto. Podría estar presente en la flora brasileña.

\section{Bromelia poeppigii Mez}

\section{CR, Blab(iii)}

Publicación: Fl. Bras. 3(3): 188. 1891. Colección tipo: E.F. Poeppig 1824

Herbarios:

Nombre común: D esconocido.

Registro departamental: SM.

Regiones Ecológicas: BHA; altitud desconocida.

SINANPE: Sin registro.

Herbarios peruanos: Ninguno.

Observaciones: Hierba epífita conocida sólo de la colección tipo. La localidad original está ubicada en la cuenca del Huallaga. Aunque esta zona ha sido herborizada consecutivamente, sus ambientes naturales han sido modificados por la ampliación agrícola. Al parecer, no ha vuelto a ser recolectada desde 1830.

\section{Bromelia tarapotina Ule}

$$
\text { EN, B1a }
$$

Publicación: Verh. Bot. Vereins Prov. Brandenburg 48: 130. 1907.

Colección tipo: E.H.G. Ule 6682

Hemanios: B.

Nombre común: D esconocido.

Registro departamental: LO, SM.

Regiones Ecológicas: BHA; 150-300 m.

SINAN PE: RNAM

Herbarios peruanos: USM (1).

Observaciones: Hierba conocida de cuatro localidades, en el oriente del país, en las cuencas del Huallaga, Mayo y Amazonas. Estas localidades están aisladas entre ellas, dentro de un área aproximada de $4000 \mathrm{~km}^{2}$. 
12. Fosterella aletroides (L.B. Sm.) L.B. Sm.

$$
\text { CR, Bla }
$$

Publicación: Phytologia 7(4): 171. 1960. Colección tipo: C. Vargas C. 7358

Herbarios: US.

Nombre común: D esconocido.

Registro departamental: CU.

Regiones Ecológicas: BMHP; $900 \mathrm{~m}$.

SINAN PE: Sin registro.

Herbarios peruanos: Ninguno.

Observaciones: Esta especie terrestre es conocida sólo de una localidad, al parecer, no ha vuelto a ser recolectada desde 1948. Probablemente, lo poco herborizado que es la altitud, donde crece esta especie, contribuya a que no se conozca más sobre ella.

\section{Greigia leymebambana $\mathrm{H}$. Luther}

$$
\text { CR, Blab(iii) }
$$

Publicación: Selbyana 23: 49, f. 3. 2002. Colección tipo: V. Quipuscoa et al. 1343 Hemanios: MO, SEL; HAO!, HUT!

Nombre común: Sacha piña.

Registro departamental: AM.

Regiones Ecológicas: BMHM; 2700$2950 \mathrm{~m}$.

SINANPE: Sin registro.

Herbarios peruanos: HAO (isotipo), HUT (isotipo).

Observaciones: Esta especie herbácea se conoce de un solo ejemplar recolectado en 1998, en la cuenca del Utcubamba. La localidad tipo se halla en el área de influencia de un sitio arqueológico y tal vez esto permita algo de protección a esa población. Sin embargo, de acuerdo con Sagástegui et al. (2003), las amenazas principales a sus poblaciones están asociadas a la deforestación.

\section{Greigia macbrideana L.B. Sm.}

\section{EN, Bla}

Publicación: Contr. Gray Herb. 98: 7, t. 1, f. 9-11. 1932.

Colección tipo: J.F. Macbride 4442

Herbarios: $F$.

Nombre común: Sacha piña.

Registro departamental: AM, HU.

Regiones Ecológicas: PSH, BPM; 3700

SINAN PE: Sin registro.

Herbarios peruanos: Ninguno.

Observaciones: Esta hierba terrestre es conocida de dos localidades, en la vertiente oriental del país. La localidad original está ubicada en la cuenca alta del Huallaga, en una zona escasamente herborizada

\section{Greigia raponum $\mathrm{H}$. Luther}

$$
\text { EN, Bla }
$$

Publicación: Selbyana 19(2): 224, f. 5. 1998.

Colección tipo: B. Boyle et al. 4373

Hemanios: F; USM.

Nombre común: Desconocido.

Registro departamental: CU, JU.

Regiones Ecológicas: BPM; $3320 \mathrm{~m}$.

SINAN PE: PNO

Herbarios peruanos: USM (holotipo).
Observaciones: Esta hierba terrestre es conocida solamente de la colección tipo, una planta recolectada en la cuenca del Apurímac y en la zona que ocupa el Parque Nacional Otishi.

\section{Greigia vilcabambaeH. Luther}

$$
\text { EN, B1a }
$$

Publicación: Selbyana 19(2): 225, f. 6. 1998.

Colección tipo: B. Boyle et al. 4826

Herbarios: F; USM.

Nombre común: Desconocido.

Registro departamental: CU, JU.

Regiones Ecológicas: BMHM; $2090 \mathrm{~m}$.

SINANPE: PNO

Herbarios peruanos: USM (holotipo).

Observaciones: Hierba terrestre descrita de una planta recolectada, en 1997, en la Cordillera deVilcabamba. Amenazas a sus poblaciones provienen de losincendiosintencionales y expansión de laagricultura.

\section{Guzmania bismanckii Rauh}

\section{CR, Bla}

Publicación: Trop. Subtrop. Pflanzenwelt 50(15): 19, f. 8. 1984.

Colección tipo: W. Rauh \& K. von Bismarck 63679

Herbarios: HEID.

Nombre común: Desconocido.

Registro departamental: SM.

Regiones Ecológicas: BMHP; $800 \mathrm{~m}$.

SINANPE: Sin registro.

Herbarios peruanos: Ninguno.

Observaciones: Esta hierba terrestre está, al parecer, restringida a la cuenca del Mayo, en una localidad de suelos arenosos. Podría estar representada en los alrededores del Bosque de Protección del Alto Mayo. Los ambientes, en la altitud que se conoce esta especie, están afectados por la expansión agrícola.

\section{Guzmania brevispatha Mez}

\section{CR, B lab(iii)}

Publicación: Repert. Spec. Nov. Regni Veg. 3: 45. 1906.

Colección tipo: A. Weberbauer 3537

Herbarios: B; MOL!.

Nombre común: D esconocido.

Registro departamental: HU.

Regiones Ecológicas: BMHM; 2000$2500 \mathrm{~m}$.

SINANPE: Sin registro.

Herbarios penuanos: MOL (isotipo).

Observaciones: Esta hierba terrestre es conocida sólo de la colección tipo, una planta proveniente de la cuenca del Monzón, tributario del Huallaga. Esa cuenca ha sido escasamente herborizada los últimos 50 años. La deforestación asociada a la expansión agrícola podría ser tema preocupante para esta especie. 


\section{Guzmania cuzcoensis L.B. Sm.}

\section{CR, B 1ab(iii)}

Publicación: Phytologia 24: 445, t. 5, f. 7, 8. 1972.

Colección tipo: T.R. Dudley 11317

Herbarios: NA.

Nombre común: D esconocido.

Registro departamental: CU.

Regiones Ecológicas: BMHM; 2150$2200 \mathrm{~m}$.

SINANPE: Sin registro.

Herbarios peruanos: Ninguno.

Observaciones: Hierba conocida sólo de la colección tipo, recolectada en lavertiente occidental delaCordillera deVilcabamba, en la cuencadel Apurímac, al sur del Parque Nacional O tishi. Al parecer, no ha vuelto a ser recolectada desde 1968. Fuera del área protegida, amenazas a sus poblaciones proviene de los incendios intencionales.

\section{Guzmania diazii H. Luther}

\section{EN, Bla}

Publicación: Brittonia 54(4): 281, f. 3. [2003] 2002.

Colección tipo: C. Díaz et al. 7684a

Herbarios: MO, SEL; USM!

Nombre común: D esconocido.

Registro departamental: AM.

Regiones Ecológicas: BHA; 550- $700 \mathrm{~m}$.

SINANPE: Sin registro.

Herbarios peruanos: USM (isotipo).

Observaciones: Esta hierba terrestre es conocida de dos poblaciones, ambas en la cuenca del Imaza, tributario del Marañón.Poco se sabe del tamaño de sus poblaciones y de otros requisitos ambientales. Sin embargo, por tratarse de una especie que crece en el sotobosque, la deforestación podría ser un problema.

\section{Guzmania lindeni (André) Mez lindeni}

$$
\text { EN, Bla }
$$

Publicación:

Colección tipo: Germiny Hortus s.n.

Herbarios: LG.

Nombre común: D esconocido.

Registro departamental: SM.

Regiones Ecológicas: BHA; $400 \mathrm{~m}$.

SINAN PE: Sin registro.

Herbarios peruanos: Ninguno.

Observaciones: Este taxón herbáceo fue descrito de un ejemplar en cultivo procedente del Perú, pero sin detalles de la localidad. Una población silvestre es conocidaen el nor-orientedel país, en la cuencadel Mayo, tributario del Huallaga. En Brako \& Zarucchi (1993) se incluyea Junín como parte de la distribución de este taxón, pero Rauh (1983) consideró al ejemplar de Junín como un taxón distinto.

\section{Guzmania lindeni (André) Mez concolor Rauh CR, B1ab(iii)}

Publicación: Trop. Subtrop. Pflanzenwelt 43(14): 41-46, f. 27. 1983.

Colección tipo: W. Rauh \& K. von Bismarck 31312

Herbarios: HEID, US.

Nombre común: D esconocido.

Registro departamental: JU.

Regiones Ecológicas: BMHP; $1200 \mathrm{~m}$.

SINANPE: Sin registro.

Herbarios peruanos: Ninguno.
Observaciones: Esta variedad es conocida de la colección tipo, una planta proveniente de la cuenca del Tulumayo, un afluente del Perené. A parentemente no ha vuelto a ser recolectada desde 1977. Los ambientes naturales en esa cuenca están influenciados por las actividades agrícolas y la expansión rural.

\section{Guzmania nio-nievensis Rauh}

\section{DD}

Publicación: Trop. Subtrop. Pflanzenwelt 50(15): 22-23, f. 10. 1984

Colección tipo: W. Rauh \& K. von Bismarck 63687a

Herbarios: HEID.

Nombre común: D esconocido.

Registro departamental: AM, SM.

Regiones Ecológicas: BMHM; altitud desconocida.

SINAN PE: Sin registro.

Herbarios peruanos: Ninguno.

Observaciones: Esta hierba es conocida solamente de la colección tipo, una planta, al parecer, recolectada entre el sur del departamento de Amazonas y el nor-occidente de San Martín. El nombre de esta especie la vincula a la cuenca del río Nieva; sin embargo, los datos de la colección tipo no corresponden a esa localidad.

\section{Guzmania victoriae Rauh}

$$
\text { EN, Bla }
$$

Publicación: Trop. Subtrop. Pflanzenwelt 18(6): 24. 1976.

Colección tipo: W. Rauh 38336

Herbarios: HEID, US.

Nombre común: D esconocido.

Registro departamental: AM, SM.

Regiones Ecológicas: BMHM; $2200 \mathrm{~m}$.

SINAN PE: Sin registro.

Herbarios peruanos: Ninguno.

Observaciones: Esta hierba terrestre es conocida de dos localidades, en los bosques montanos del nor-oriente del país. El ejemplar tipo, al parecer, fue recolectado en Amazonas y es considerada localmente rara. La otra localidad conocida está en la cuenca alta del Mayo y es probable que otras poblaciones se encuentren en el Bosque de Protección del Alto Mayo.

\section{Guzmania vinidiflora E. Gross}

$$
\text { CR, Blab(iii) }
$$

Publicación: Trop. Subtrop. Pflanzenwelt 95: 21, t.15. 1997.

Colección tipo: W. Rauh 63742

Hemarios: HEID.

Nombre común: D esconocido.

Registro departamental: AM.

Regiones Ecológicas: BMHM; $1800 \mathrm{~m}$.

SINANPE: Sin registro.

Henbarios peruanos: Ninguno.

Observaciones: Esta hierba epífita es conocida sólo de la colección tipo, proveniente de la cuenca del Huallabamba, donde al parecer, no ha vuelto a ser recolectada desde 1983. Amenazas potenciales están asociadas a la deforestación. 
26. Guzmania xipholepis L.B. Sm.

$$
\text { EN, Bla }
$$

Publicación: Phytologia 9(4): 248, t.2, f. 7, 8. 1963.

Colección tipo: J.J. Wurdack 917

Hemarios: NY, US; USM.

Nombre común: D esconocido.

Registro departamental: AM, PA.

Regiones Ecológicas: BMHM; 2300$2700 \mathrm{~m}$.

SINANPE: Sin registro.

Herbarios peruanos: USM (isotipo citado).

Observaciones: Esta hierba epífita es conocida de dos localidades, en el norte y centro del país, en localidades separadas por aproximadamente $300 \mathrm{~km}$ en línea recta. La localidad original está ubicada, en una zona de alto endemismo, en la cuenca del Chiriaco, la que no recibe protección alguna. La segunda población se halla en la cuenca alta del Pozuzo. O tras localidades atribuidas a esta especie están basadas en identificaciones dudosas. Podría estar representada en el Parque Nacional Yanachaga-Chemillén.

\section{Neoregelia eleutheropetala (Ule) L.B. Sm. bicolor} L.B. Sm.

DD

Publicación: Phytologia 8(5): 227. 1962.

Colección tipo: L. Moore s.n.

Herbarios: NY, US.

Nombre común: D esconocido.

Registro departamental: LO.

Regiones Ecológicas: BHA; altitud desconocida.

SINAN PE: Sin registro.

Herbarios peruanos: Ninguno.

Observaciones: Este taxón epífito es conocido, al parecer, de la colección tipo, una planta de procedencia exacta desconocida. No ha vuelto a ser recolectada desde 1961.

\section{Neoregelia wurdackii L.B. Sm.}

$$
\text { EN, Bla }
$$

Publicación: Phytologia 9(4): 244, t.1, f. 3-5. 1963.

Colección tipo: J.J. Wurdack 2469

Hembarios: NY, US; USM!.

Nombre común: D esconocido.

Registro departamental: AM.

Regiones Ecológicas: BHA; 300-350 m. SINANPE: ZRSC

Hembarios peruanos: USM (isotipo).

Observaciones: Esta hierba epífita es conocida sólo de las cuencas de Santiago y del Imaza. Fue descrita de una planta recolectada en 1962, en una localidad hoy en laZona Reservada Santiago-Comaina.

\section{Pepinia holstii H. Luther}

\section{CR, Bla}

Publicación: J. Bromeliad Soc. 51(2): 7172, f. 10-11. 2001

Colección tipo: B. Holst \& H. Luther 7277

Herbarios: SEL; USM!.

Nombre común: D esconocido.

Registro departamental: CU.

Regiones Ecológicas: BMHP; 950-1000 m.

SINAN PE: Sin registro.

Herbarios peruanos: USM (isotipo).
Observaciones: Esta especie herbácea fue descrita de una planta cultivada, desarrollada de una semilla extraída del ejemplar Holst \& Beltrán 6541 en SEL (Luther, 2001), la cual fue recolectada en la Cordillera de Vilcabamba.

\section{Pepinia minicorallina H. Luther}

$$
\text { EN, Bla }
$$

Publicación: Selbyana 21(1,2): 130-131, f. 6. 2000 .

Colección tipo: R. Rojas et al. 456

Herbarios: MO, SEL.

Nombre común: Desconocido.

Registro departamental: AM.

Regiones Ecológicas: $\mathrm{BMHP}, \mathrm{BHA}$; $300-800 \mathrm{~m}$.

SINAN PE: Sin registro.

Hembarios peruanos: Ninguno.

Observaciones: Esta hierba terrestre es conocida sólo de la cuenca del Imaza, en el nor-oriente del país, en un rango de $500 \mathrm{~m}$ de altitud. Las localidades conocidas se hallan en el territorio de comunidades Aguarunas.

\section{Pepinia neglecta H. Luther}

DD

Publicación: Phytologia 74(6): 456, f. 4. 1993. Colección tipo: J. Halton \& L. Besse ex H.E. Luther s.n.

Herbarios: SE L, US; USM!.

Nombre común: D esconocido.

Registro departamental: SM.

Regiones Ecológicas: BMHP; 1000 m.

SINAN PE: Sin registro.

Herbarios penuanos: USM (isotipo).

Observaciones: El ejemplar tipo y las colecciones que se conocen de esta especie herbácea, provienen de una planta en cultivo. originalmente recolectada, probablemente, entre las cuencas del Mayo y Huallaga.

\section{Pepinia penuana H. Luther}

\section{EN, B 1ab(iii)}

Publicación: Selbyana 23: 49, f. 4. 2002. Colección tipo: J. Campos \& S. Corrales 3556

Hemarios: MO, SEL.

Nombre común: D esconocido.

Registro departamental: AM, CA.

Regiones Ecológicas: BMHM; 1950$2000 \mathrm{~m}$.

SINANPE: ZRCC

Herbarios peruanos: Ninguno.

Observaciones: Esta hierba terrestre es conocida de las cuencas del Chinchipe y del Imaza, en el norte del Perú, de localidades que distan aproximadamente $100 \mathrm{~km}$ entre ellas. La recolecta más antigua proviene de la La Peca, hoy en la Zona Reservada Cordillera Colán, un área con alto endemismo, pero severamente afectada por la deforestación. 


\section{Pitcairnia acicularis L.B. Sm.}

\section{EN, Bla}

Publicación: Publ. Mus. Hist. Nat. «Javier Prado», Ser. B, Bot. 13: 3-4, figs. 4-5. 1963.

Colección tipo: R. Ferreyra 14167

Henbarios: US; USM!.

Nombre común: D esconocido

Registro departamental: AN, LA.

Regiones Ecológicas: MDE, MA; 1800$3600 \mathrm{~m}$.

SINANPE: PNH

Herbarios peruanos: CPUN (1), USM (holotipo).

Observaciones: Esta hierba terrestre es conocida sólo de dos localidades, en la vertiente occidental del norte del país, en las cuencas del O lmosy Santa. O cupa laderas con matorrales subxéricos.

\section{Pitcairnia ancuashii L.B. Sm. \& Read \\ CR, Bla}

Publicación: Phytologia 41(5): 330. 1979.

Colección tipo: E. Ancuash A. 519

Herbarios: MO, US.

Nombre común: D esconocido.

Registro departamental: AM.

Regiones Ecológicas: BHA; $250 \mathrm{~m}$.

SINAN PE: Sin registro.

Herbarios peruanos: Ninguno.

Observaciones: Hierba conocida sólo de la colección tipo, una planta proveniente de la cuenca del Cenepa. Probablemente esté presente en la Z ona Reservada Santiago-Comaina. Aparentemente no ha vuelto a ser recolectada desde 1973.

\section{Pitcairnia arenaria H. Luther}

\section{EN, Bla}

Publicación: Selbyana 23: 49, f. 5. 2002. Colección tipo: H. van der Werff et al. 15815 Herbarios: MO, SEL.

Nombre común: D esconocido.

Registro departamental: AM, CA.

Regiones Ecológicas: BMHM; 1800$2550 \mathrm{~m}$.

SINANPE: Sin registro.

Herbarios penuanos: HUT (1).

Observaciones: Esta hierba terrestre es conocida de las cuencas del Chinchipe y del Chiriaco, en el norte del país. Esta especie podría tratarse de una especialista edáfica, pues ocupa suelos arenosos. Las localidades conocidas se hallan en lazona de influencia dela Cordillera del Cóndor.

\section{Pitcairnia asplundii L.B. Sm.}

\section{EN, Bla}

Publicación: Phytologia 4(4): 214, t. 1, figs. 6- 9. 1953

Colección tipo: E. Asplund 12263

Herbarios: S.

Nombre común: D esconocido.

Registro departamental: AM, HU.

Regiones Ecológicas: BMHP; 500— 750 m.

SINANPE: Sin registro.

Herbarios peruanos: Ninguno.
Observaciones: Hierba epífita conocida de dos localidades, en el oriente del país. El ejemplar tipo proviene de la cuenca del Huallaga, recolectado en 1940. Otra población ha sido registrada en la cuenca del Cenepa, distante de la localidad original por más de $400 \mathrm{~km}$ en línea recta. Podría estar representada en el Parque Nacional Tingo Mańa.

\section{Pitcaimia attenuata L.B. Sm. \& Read}

$$
\text { CR, Blab(iii) }
$$

Publicación: Phytologia 41(5): 329. 1979. Colección tipo: J. Schunke V. 8078

Herbarios: MO, US.

Nombre común: D esconocido.

Registro departamental: SM.

Regiones Ecológicas: BHA; 700- $800 \mathrm{~m}$. SINAN PE: Sin registro.

Herbarios peruanos: Ninguno.

Observaciones: Hierba terrestre conocida solamente de una localidad, ubicada en el distrito de Uchiza. Esta especie fue descrita de una planta recolectada en 1974, creciendo sobre rocas en el sotobosque. Amenazas a sus poblaciones provienen de la deforestación.

\section{Pitcairnia augustii Harms \\ CR, Bla}

Publicación: Notizbl. Bot. Gart. BerlinDahlem 10: 211. 1928.

Colección tipo: A. Weberbauer 7074

Hemarios: B; MOL!.

Nombre común: D esconocido.

Registro departamental: LL.

Regiones Ecológicas: BMHM; 2200$2300 \mathrm{~m}$.

SINAN PE: Sin registro.

Herbarios penuanos: MOL (isotipo).

Observaciones: Especie herbácea conocida de una localidad, en la cuenca del Mixiollo, al sur del Parque Nacional Río Abiseo, donde fue recolectada en 1914. Colecciones recientes en ese Parque, no han derivado en nuevas colecciones de esta especie.

\section{Pitcairnia bifania L.B. Sm.}

\section{CR, Blab(iii)}

Publicación: Phytologia 21(2): 91, t. 3, f. 1-3. 1971.

Colección tipo: T.R. Dudley 13887

Hemarios: MO, NA.

Nombre común: D esconocido.

Registro departamental: HU.

Regiones Ecológicas: BMHP; $1400 \mathrm{~m}$.

SINANPE: RCS

Herbarios peruanos: Ninguno.

Observaciones: Esta hierba epífita es conocida solamente de la localidad original, en la cuenca del Pachitea. Esta especie, al parecer, no ha vuelto a ser recolectada desde 1969. Si bien esta zona forma parte de una Reserva Comunal, las partes más bajas están proclives a modificación de hábitat por actividad humana. 


\section{Pitcairnia calatheoides L.B. Sm.}

$$
\text { EN, Blab(iii) }
$$

Publicación: Contr. Gray Herb. 117: 24, t.2, f. 8-11. 1937.

Colección tipo: G. Klug 4237

Herbarios: F, GH, NY, US.

Nombre común: Desconocido.

Registro departamental: HU, SM.

Regiones Ecológicas: BMHP; 400-800 m.

SINAN PE: Sin registro.

Hembarios peruanos: Ninguno.

Observaciones: Esta especie herbácea es conocida de localidades dispersas, en la cuenca del Huallaga. A parentemente sólo dos poblaciones han sido registradas hasta 1978. Ambas localidades podrían haber sido afectadas por las actividades agrícolas.

\section{Pitcairnia camposii H. Luther}

$$
\text { EN, B1a }
$$

Publicación: Selbyana 23: 53, f. 6. 2002. Colección tipo: J. Campos \& P. Díaz 4416 Herbarios: MO, SEL; HUT!.

Nombre común: D esconocido.

Registro departamental: CA.

Regiones Ecológicas: BMHM; 1600$1700 \mathrm{~m}$.

SINANPE: Sin registro.

Hemarios penuanos: HUT (isotipo).

Observaciones: Esta especie se conoce de un solo ejemplar, recolectado en 1997, en la cuenca del Marañón. Probablemente ocupe áreas abiertas y con vegetación secundaria.

\section{Pitcairnia cassapensis Mez}

\section{DD}

Publicación: Repert. Spec. Nov. Regni Veg. 16: 8. 1919.

Colección tipo: E.F. Poeppig 1526

Herbarios: W.

Nombre común: D esconocido.

Registro departamental: CU, HU.

Regiones Ecológicas: BMHP; altitud desconocida.

SINANPE: Sin registro.

Herbarios peruanos: Ninguno.

Observaciones: Hierba conocida de unas pocas localidades dispersas, en la vertiente oriental. La localidad original se encuentra en la cuenca del Huallaga y esa población, al parecer, no ha vuelto a registrarse desde el siglo XIX.

\section{Pitcairnia cerrateana L.B. Sm.}

\section{DD}

Publicación: Phytologia 70(1): 52. 1991. Colección tipo: E. Cerrate 8967

Herbarios: USM.

Nombre común: Desconocido.

Registro departamental: AN.

Regiones Ecológicas: MA; 1800-1900 m.

SINAN PE: Sin registro.

Herbarios peruanos: USM (tipo citado).

Observaciones: Hierba terrestre conocida de laderas semixéricas, de la Cordillera Negra, en la cuenca del Santa. Esta zona requiere de un estudio más detallado para reubicar estas poblaciones.

\section{Pitcairnia clavata L.B. Sm.}

\section{DD}

Publicación: Phytologia 9(4): 248-249, t.2, f. 9, 10. 1963.

Colección tipo: J.J. Wurdack 2419

Henbarios: US.

Nombre común: D esconocido.

Registro departamental: LO.

Regiones Ecológicas: BHA; $250 \mathrm{~m}$.

SINANPE: Sin registro.

Herbarios peruanos: Ninguno.

Observaciones: Esta especie se conoce dela cuenca del río Marañón. Aparentemente, no ha vuelto a ser recolectada desde 1962.

\section{Pitcairnia cyanopetala Ule}

\section{DD}

Publicación: Verh. Bot. Vereins Prov. Brandeburg 48: 139. 1907.

Colección tipo: E.H.G. Ule 6608

Herbarios: B.

Nombre común: D esconocido.

Registro departamental: SM.

Regiones Ecológicas: BMHP; 1400 m.

SINANPE: ACRCE

Herbarios peruanos: Ninguno.

Observaciones: Hierba terrestre conocida del ejemplar tipo, probablemente destruido durante la Segunda Guerra Mundial. Esta especie fue recolectada a inicios del siglo XX, de Cerro la Escalera, localidad recientemente reconocida como un área protegida.

\section{Pitcairnia decurvata L.B. Sm.}

$$
\text { VU, Bla }
$$

Publicación: Phytologia 10(1): 36- 37, t.1, f. 8, 9. 1964.

Colección tipo: A. López M. et al. 4047

Herbarios: HUT.

Nombre común: D esconocido.

Registro departamental: AN, CA, LA. Regiones Ecológicas: PSH; 1800-3850 m. SINAN PE: Sin registro.

Herbarios penuanos: CPUN (1), HAO (1), HUT (isotipo citado).

Observaciones: Especie herbácea descrita de una planta recolectada en 1963, de la cuenca del Choloque. Es conocida de vertientes occidentales y valles interandinos.Ambas regiones escasamente herborizadas para esta familia.

\section{Pitcairnia ellenbergii L.B. Sm.}

\section{DD}

Publicación: Phytologia 15(3): 194, t. 3, f. 36-37. 1967.

Colección tipo: H. Ellenberg 993

Herbarios: U, US.

Nombre común: D esconocido.

Registro departamental: CU.

Regiones Ecológicas: BMHM; 2000 m.

SINANPE: Sin registro.

Herbarios peruanos: Ninguno.

Observaciones: Hierba que crece en laderas rocosas, conocida solamente de una localidad en la cuenca del Urubamba, muy cerca al Santuario Histórico de Machu Picchu. Aparentemente no ha vuelto a ser recolectada desde 1957. 


\section{Pitcairnia eximea Mez}

\section{DD}

Publicación: Repert. Spec. Nov. Regni Veg. 3: 5-6. Como «eximia». 1906.

Colección tipo: A. Weberbauer 2025

Hemarios: B.

Nombre común: D esconocido.

Registro departamental: JU.

Regiones Ecológicas: BMHM; 1900$2000 \mathrm{~m}$.

SINANPE: Sin registro.

Herbarios peruanos: Ninguno.

Observaciones: Este especie herbácea es conocida sólo de una localidad, ubicada en los alrededores de Huacapistana. Estapoblación fue recolectada en 1903 y aparentemente, no ha vuelto a ser registrada.

\section{Pitcairnia ferreyrae L.B. Sm.}

\section{DD}

Publicación: Phytologia 4(4): 215, t. 1, f. 10-12. 1953.

Colección tipo: R. Ferreyra 1044

Herbarios: US; USM!.

Nombre común: D esconocido.

Registro departamental: UC.

Regiones Ecológicas: BMHM, BMHP; 1500- $1600 \mathrm{~m}$.

SINAN PE: Sin registro.

Herbanios penuanos: USM (isotipo).

Observaciones: Hierba descrita de una planta recolectada en la cuenca del Aguaytía. Probablemente se halle en el Parque Nacional Cordillera Azul.

\section{Pitcairnia filifera L.B. Sm. ex H. Luther}

\section{DD}

Publicación: Brittonia 54(4): 285, f. 4. [2003] 2002.

Colección tipo: W. Rauh 20874

Herbarios: US.

Nombre común: D esconocido.

Registro departamental: CU.

Regiones Ecológicas: BMHP; 1300 m.

SINANPE: Sin registro.

Hemarios peruanos: Ninguno.

Observaciones: Hierba que se conoce solamente del ejemplar tipo, procedente de la cuenca del Urubamba y recolectado en 1967, en los alrededores de Quillabamba, en ambientes rocosos. Los ambientes naturales de esa parte de la cuenca están afectados por las actividades agrícolas, pero se desconoce el estado de sus poblaciones.

\section{Pitcaimia fimbriato-bracteata Rauh}

\section{CR, Bla}

Publicación: Trop. Subtrop. Pflanzenwelt 53(17): 48-51, f. 25. 1985.

Colección tipo: W. Rauh \& K. von Bismarck 40180

Herbarios: HEID, US.

Nombre común: D esconocido.

Registro departamental: AM.

Regiones Ecológicas: BMHP; $700 \mathrm{~m}$.

SINANPE: Sin registro.

Herbarios peruanos: Ninguno.
Observaciones: Hienba terrestre conocida aparentemente sólo de la colección tipo. Al parecer habita ambientes con vegetación secundaria.

52. Pitcairnia fractifolia L.B. Sm.

\section{DD}

Publicación: Phytologia 10(1): 37, t. 1, f. 10, 11. 1964.

Colección tipo: A. López M. et al. 4242

Hemanios: HUT, US; HUT!.

Nombre común: D esconocido.

Registro departamental: AM.

Regiones Ecológicas: BS; $800 \mathrm{~m}$.

SINAN PE: Sin registro.

Herbarios peruanos: HUT (isotipo+1).

Observaciones: Hierba conocida aparentemente de dos poblaciones, en la cuenca del Utcubamba. Esta especie fue descrita de una planta recolectada en 1963, en laderas rocosas con vegetación xérica. Al igual que otras especies en la familia existen pocos registros de herbario e información sobre sus poblaciones.

\section{Pitcairnia gutteana $\mathrm{W}$. Weber}

\section{DD}

Publicación: Cat. Herb. Lips. Plant. Peru II:40. 1984.

Colección tipo: P. Gutte et al. 1423

Herbarios: LZ.

Nombre común: D esconocido.

Registro departamental: LO.

Regiones Ecológicas: BHA; altitud desconocida.

SINAN PE: Sin registro.

Herbarios peruanos: Ninguno.

Observaciones: Esta planta herbácea es conocida aparentemente sólo de la colección tipo, procedente de una localidad no precisada atribuida a Loreto. Se desconoce el estado de sus poblaciones.

\section{Pitcairnia inermis L.B. Sm. flava L.B. Sm.}

\section{DD}

Publicación: Phytologia 5(2): 46. 1954.

Colección tipo: R. Ferreyra 4228

Herbarios: USM.

Nombre común: D esconocido.

Registro departamental: HU.

Regiones Ecológicas: BMHP; 800-900 m. SINANPE: Sin registro.

Herbarios penuanos: USM (holotipo citado).

Observaciones: Este taxón herbáceo se caracteriza por las flores amarillas que le dan nombre. Solamente se conoce de la localidad original en el centro del país. Se desconoce el estado de sus poblaciones.

\section{Pitcairnia juzepczukii W. Weber}

\section{DD}

Publicación: Feddes Repert. 97: 95, f. 2. 1986. Colección tipo: S.V. Juzepczuk 10310

Herbarios: LE.

Nombre común: D esconocido.

Registro departamental: JU.

Regiones Ecológicas: BMHM; 2500 m.

SINANPE: Sin registro.

Herbarios peruanos: Ninguno. 
Observaciones: Hierba conocida solamente de la colección tipo, una planta recolectada en 1927, de la cuenca alta del Palca. La localidad original, Huacapistana, alberga varios endemismos y no recibe protección alguna. Si bien no se conocen las características del hábitat de esta especie, ni de sus poblaciones, los ambientes naturales de esa parte del país han sido extensamente modificados por la ampliación agrícola y de caminos.

\section{Pitcairnia lopezii L.B. Sm.}

\section{EN, Blab(iii)}

Publicación: Phytologia 5(2): 46, 48, t. 6, f. 4-6. 1954.

Colección tipo: A. López M. 226

Herbarios: US.

Nombre común: D esconocido.

Registro departamental: LL.

Regiones Ecológicas: D ST, MA; 490$2040 \mathrm{~m}$.

SINANPE: Sin registro.

Herbarios peruanos: AMAZ (1), HAO

(1), HUT (isotipo+7).

Observaciones: Esta especie se conoce de varias localidades en el nor-centro del país. Estas localidades están naturalmente fragmentadas, pues incluyen islas de vegetación en la costa y roquedales en las estribaciones andinas. La mayoría delas colecciones provienen de la localidad original en Cerro Campana. Amenazas provienen de la expansión urbana y actividades asociadas, especialmente para la población de la localidad original.

\section{Pitcairnia melanopoda L.B. Sm.}

\section{DD}

Publicación: Phytologia 9(4): 249, t. 2, f. 11-13. 1963.

Colección tipo: J.J. Wurdack 1070

Herbarios: US; USM.

Nombre común: D esconocido.

Registro departamental: AM.

Regiones Ecológicas: BMHM; 2050$2400 \mathrm{~m}$.

SINAN PE: Sin registro.

Herbarios peruanos: HUT (1), USM (isotipo citado).

Observaciones: Esta hierba terrestre es conocida al parecer, de dos poblaciones de la cuenca del Chiriaco. Las plantas conocidas de esta especie fueron recolectadas en los años 1960. No se conoce la situación de sus poblaciones.

\section{Pitcairnia pallidiflavens Rauh}

\section{DD}

Publicación: Trop. Subtrop. Pflanzenwelt 52(16):23, f. 12-13. 1985.

Colección tipo: W. Rauh 53674

Herbarios: HEID.

Nombre común: D esconocido.

Registro departamental: SM.

Regiones Ecológicas: BMHP; 800 m.

SINAN PE: Sin registro.

Herbarios peruanos: Ninguno.

Observaciones: Especie herbácea que crece en suelos arenosos, en áreas abiertas con orquídeas, en una localidad no precisada, en la cuenca del Huallaga. No se conoce la situación de sus poblaciones.

\section{Pitcairnia poeppigiana Mez}

EN, Bla

Publicación: Fl. Bras. 3(3): 461. 1894.

Colección tipo: E.F. Poeppig 2424

Hembarios: W.

Nombre común: D esconocido.

Registro departamental: LO.

Regiones Ecológicas: BHA; 110-150 m.

SINAN PE: Sin registro.

Herbarios peruanos: Ninguno.

Observaciones: Hierba terrestre conocida de unas pocas poblaciones, entre las cuencas del Huallaga medio y del Nanay. Esta especie fue descrita de una planta recolectada en el siglo XIX, en los alrededores de Yurimaguas. El hábitat de esta especie incluye bosques sobre suelos arenosos, los que en algunos casos están siendo deforestados.

\section{Pitcaimia pomacochae Rauh}

\section{LC}

Publicación: Trop. Subtrop. Pflanzenwelt 33(10): 121. 1981.

Colección tipo: W. Rauh 24566

Herbarios: HEID ; USM!.

Nombre común: D esconocido.

Registro departamental: AM, CA, PA.

Regiones Ecológicas: BMHP; 700- 2300

m.

SINANPE: Sin registro.

Herbarios peruanos: HUT (2), USM (isotipo).

Observaciones: Hierba terrestre conocida de varias poblaciones, desde los límites con Ecuador hasta el centro del país. Esta especie fue descrita de una planta cuyo origen, erróneamente, se atribuyó a San Martín, pero que en realidad la localidad está ubicada en Amazonas. Podría estar representada en la flora ecuatoriana.

\section{Pitcairnia pseudopungens Rauh}

Publicación: Trop. Subtrop. Pflanzenwelt 75:13, f. 6. 1990.

Colección tipo: W. Rauh 52797

Herbarios: HEID.

Nombre común: D esconocido.

Registro departamental: AM. Regiones Ecológicas: BS; $1200 \mathrm{~m}$.

SINAN PE: Sin registro.

Herbarios peruanos: Ninguno.

Observaciones: Este taxón fue considerado en Brako \& Zarucchi (1993) como un endemismo; sin embargo, no ha sido posible evaluarlo, ni asignarle una categoría.

\section{Pitcairnia pseudoundulata Rauh}

Publicación: Bromelie 1985(3): 27. 1985.

Colección tipo: W. Rauh 40159

Herbarios: HEID.

Nombre común: Desconocido.

Registro departamental: AM.

Regiones Ecológicas: BMHP; $800 \mathrm{~m}$.

SINANPE: Sin registro.

Herbanios peruanos: Ninguno. 
Observaciones: Hierba conocida de la cuenca del Imaza. Este taxón fue considerado por Brako \& Zarucchi (1993) como un endemismo; sin embargo, no ha sido posible evaluarlo, ni asignarle una categoná.

\section{Pitcairnia puyoides L.B. Sm.}

\section{DD}

Publicación: Field Mus. Nat. Hist., Bot. Ser. 11(5):147. 1936.

Colección tipo: G. Klug 3547

Herbarios: F, GH, MO, NY, US.

Nombre común: D esconocido.

Registro departamental: SM.

Regiones Ecológicas: BMHP; $1200-$ $1600 \mathrm{~m}$.

SINANPE: Sin registro.

Herbarios peruanos: Ninguno.

Observaciones: Hierba epífita conocida solamente de la localidad original, en el nor-oriente del país, en la cuenca del Mayo. La única población conocida fue registrada en 1934.

\section{Pitcairnia rectiflora Rauh}

\section{DD}

Publicación: Trop. Subtrop. Pflanzenwelt 52(16): 26-28, f. 15-16. 1985.

Colección tipo: W. Rauh 53673

Herbarios: HEID.

Nombre común: D esconocido.

Registro departamental: SM.

Regiones Ecológicas: BMHP; $800 \mathrm{~m}$.

SINANPE: Sin registro.

Herbarios peruanos: Ninguno.

Observaciones: Hierba terrestre conocida de una sola población, de procedencia exacta desconocida. El ejemplar original fue recolectado en 1980. Se desconoce el estado de sus poblaciones.

\section{Pitcairnia roseoalba E. Gross \& W. Rauh}

\section{DD}

Publicación: Trop. Subtrop. Pflanzenwelt 95: 14. 1997.

Colección tipo: W. Rauh 69151

Herbarios: HEID.

Nombre común: D esconocido.

Registro departamental: PI.

Regiones Ecológicas: MDE, MA; 1200 $1800 \mathrm{~m}$.

SINANPE: Sin registro.

Hembarios peruanos: Ninguno.

Observaciones: Aquí se acepta esta especie en sentido amplio. D escrita de una planta recolectada, en la cuenca alta del Piura. Se desconoce el estado de sus poblaciones.

\section{Pitcairnia rubro-nigriflora Rauh}

\section{CR, Bla}

Publicación: Trop. Subtrop. Pflanzenwelt 50(15): 32-34, f. 17. 1984.

Colección tipo: W. Rauh 53676

Hemanios: HEID.

Nombre común: D esconocido.

Registro departamental: SM.

Regiones Ecológicas: BMHP; 800-1000 m.

SINANPE: Sin registro.

Herbarios peruanos: Ninguno.
Observaciones: Hierba rizomatosa, conocida sólo de la cuenca del Mayo. Se encuentra en cultivo en Alemania. Al parecer esta es una especie rara, si bien habita zonas con vegetación secundaria.

\section{Pitcairnia ruderalis L.B. Sm.}

\section{CR, Bla}

Publicación: Phytologia 18(3): 139-140, t. 1, f. 10, 11. 1969.

Colección tipo: M.S. Christowski 66-5b

Herbarios: WIS.

Nombre común: D esconocido.

Registro departamental: UC.

Regiones Ecológicas: BMHP; $1150 \mathrm{~m}$.

SINAN PE: Sin registro.

Herbarios peruanos: Ninguno.

Observaciones: Esta especie es conocida solamente de la colección tipo, una planta recolectada en 1966, de los pajonales en la cuenca del Unine, un afluente del Ucayali. Estos ambientes han sido manejados por la comunidad Ashaninka, por cientos de años. Esta localidad no ha recibido adecuada herborización.

\section{Pitcairnia ruiziana Mez}

\section{DD}

Publicación: DC., Monogr. Phan. 9: 420. 1896. Colección tipo: H. Ruiz \& J. Pavón s.n. Herbarios: G.

Nombre común: D esconocido.

Registro departamental: Sin datos.

Regiones Ecológicas: Sin datos; altitud desconocida.

SINAN PE: Sin registro.

Herbarios peruanos: Ninguno.

Observaciones: Esta especie se conoce solamente de un ejemplar recolectado por Ruiz \& Pavón, probablemente en alguna localidad en el centro del país.

\section{Pitcairnia sagasteguii L.B. Sm. \& Read}

\section{DD}

Publicación: Phytologia 38(2): 136. 1977. Colección tipo: A. Sagástegui A. et al. 8145

Hemarios: MO, US; HUT.

Nombre común: D esconocido.

Registro departamental: PI.

Regiones Ecológicas: MA; 1700 m.

SINAN PE: Sin registro.

Hemarios penuanos: HUT (isotipo citado).

Observaciones: Hierba conocida de la cuenca del Huancabamba. El ejemplar tipo fue recolectado en 1975. Se desconoce el estado de sus poblaciones.

\section{Pitcairnia sandemanii L.B. Sm.}

\section{DD}

Publicación: Contr. U.S. Natl. Herb. 29(11): 531, f. 87. 1954.

Colección tipo: C. Sandeman 4586

Herbarios: K.

Nombre común: D esconocido.

Registro departamental: JU.

Regiones Ecológicas: BMHM; $1680 \mathrm{~m}$.

SINAN PE: Sin registro.

Herbarios peruanos: Ninguno. 
Observaciones: Planta herbácea conocida solamente de una localidad, en el valle de Chanchamayo. El ejemplar original fue recolectado en 1943 y, al parecer, no ha vuelto a ser recolectada. Esa parte del valle ha sido extensamente modificado por ampliación vial y urbana.

\section{Pitcaimia scandens Ule}

\section{DD}

Publicación: Verh. Bot. Vereins Prov. Brandenburg 48: 140. 1907.

Colección tipo: E.H.G. Ule 6687

Herbarios: $\mathrm{B}$.

Nombre común: D esconocido.

Registro departamental: SM.

Regiones Ecológicas: BMHP; $1300 \mathrm{~m}$.

SINAN PE: ACRCE

Herbarios peruanos: Ninguno.

Observaciones: Hierba epífita conocida, al parecer, sólo de la colección tipo, una planta recolectada en 1903, de una localidad en el Area de Conservación Regional Cerro La Escalera.

\section{Pitcairnia schunkei L.B. Sm. \& Read}

$$
\text { EN, Blab(iii) }
$$

Publicación: Phytologia 30(5): 290. 1975. Colección tipo: J. Schunke V. 4995

Hemarios: F, NY, US.

Nombre común: D esconocido.

Registro departamental: SM.

Regiones Ecológicas: BHA; 350- $380 \mathrm{~m}$.

SINANPE: Sin registro.

Herbarios peruanos: Ninguno.

Observaciones: Esta especie terrestre se conoce de dos localidades, en la cuenca del Huallaga. Esta parte de la cuenca está afectada por deforestación.

\section{Pitcairnia serrulata L.B. Sm. \& Read}

\section{DD}

Publicación: Phytologia 38(2): 135. 1977. Colección tipo: B. Berlin 631

Herbarios: MO, US.

Nombre común: Kuis.

Registro departamental: AM.

Regiones Ecológicas: BHA; Altitud desconocida.

SINANPE: ZRSC

Herbarios peruanos: Ninguno.

Observaciones: Hierba terrestre conocida sólo de una localidad, de procedencia exacta desconocida. Se desconoce el estado de sus poblaciones.

\section{Pitcairnia smithiorum H. Luther}

\section{DD}

Publicación: J. Bromeliad. Soc. 41(3): 99. 1991.

Colección tipo: S. Smith \& H.L. Smith s.n.

Herbarios: SE L.

Nombre común: D esconocido.

Registro departamental: LO.

Regiones Ecológicas: BHA; altitud desconocida.

SINANPE: Sin registro.

Herbarios peruanos: Ninguno.
Observaciones: Esta especie herbácea fue descrita de una planta en cultivo, recolectada originalmente de la cuenca del Napo. No se conoce detalles de su hábitat, ni de sus poblaciones.

\section{Pitcairnia stolonifera L. B. Smith \& Read}

\section{DD}

Publicación: Phytologia 33(7): 431. 1976. Colección tipo: S.S. Tillett 673-275

Herbarios: GH, US.

Nombre común: Desconocido.

Registro departamental: AM.

Regiones Ecológicas: $\mathrm{BMHM}$; 1860 $2000 \mathrm{~m}$.

SINAN PE: Sin registro.

Hembarios peruanos: Ninguno.

Observaciones: Esta especie epífita aparentemente sólo se conoce del material tipo, una planta recolectada en la cuenca del Utcubamba.

\section{Pitcairnia subfuscopetala Rauh \& Hebding}

DD

Publicación: Trop. Subtrop. Pflanzenwelt 75: 16, t. 7. 1990.

Colección tipo: W. Rauh 24416

Herbarios: HEID.

Nombre común: D esconocido.

Registro departamental: CA.

Regiones Ecológicas: BS; 700 m.

SINANPE: Sin registro.

Herbarios peruanos: Ninguno.

Observaciones: Hierba conocida aparentemente sólo de la colección tipo, una planta recolectada en 1970, de la cuenca del Chamaya.

\section{Pitcairnia subulifera L.B. Sm.}

\section{EN, Bla}

Publicación: Phytologia 4(4): 215-216. 1953.

Colección tipo: E. Asplund 13163

Herbarios: S, US.

Nombre común: D esconocido.

Registro departamental: HU.

Regiones Ecológicas: BMHM; $2600 \mathrm{~m}$.

SINAN PE: Sin registro.

Herbarios peruanos: Ninguno.

Observaciones: Hierba terrestre conocida de una localidad, ubicada en la zona de Carpish. Estalocalidad alberga varios otros endemismos y debería recibir atención para su conservación. Al parecer, no ha vuelto a ser recolectada desde 1983.

\section{Pitcairnia tarapotensis Baker}

$$
\text { VU, Bla }
$$

Publicación: Handb. Bromel. 102. 1889.

Colección tipo: R. Spruce s.n.

Hembarios: $\mathrm{K}$.

Nombre común: D esconocido.

Registro departamental: CA, SM.

Regiones Ecológicas: BMHM, BMHP; 600- $1850 \mathrm{~m}$.

SINAN PE: Sin registro.

Hemarios penuanos: USM?.

Observaciones: Hierba terrestre conocida de varias localidades dispersas, en el norte y centro oriente del país, en las cuencas del Mayo, Chamaya y Chontabamba. 
79. Pitcairnia tatzyanae (H. Luther) D.C. Taylor \& H. Rob.

\section{EN, Bla}

Publicación: Harvard Pap. Bot. 4(1): 208. 1999.

Colección tipo: T. Wachter 48

Hembarios: F; USM!.

Nombre común: D esconocido.

Registro departamental: MD.

Regiones Ecológicas: BMHP; 700 - 1350 m.

SINANPE: PNM

Herbarios penuanos: USM (isotipo).

Observaciones: Esta especie se conoce de una localidad, en el sur del país. Fue descrita de ejemplares recolectados en el Parque Nacional Manu (Taylor \& Robinson, 1999); aparentemente no hay información de las cuencas colindantes al parque.

\section{Pitcaimia truncata L.B. Sm.}

\section{NT}

Publicación: Contr. Gray Herb. 98: 10. 1932. Colección tipo: E.P. Killip \& A.C. Smith 22414 Henbarios: F, GH, NY, US.

Nombre común: D esconocido.

Registro departamental: AM, AY, CA. Regiones Ecológicas: BMHM; 1500$2300 \mathrm{~m}$.

SINANPE: ZRSC

Herbarios peruanos: HAO (1), HUT (1), USM (1).

Observaciones: Hierba terrestre descrita de una planta recolectada en 1929, de la cuenca del A purímac. Esta especie se conoce de otras localidades en ambientes modificados de los bosques montanos del nor-oriente del país, en las cuencas del Tabaconas y Chinchipe.

\section{Pitcaimia utcubambensis Rauh}

\section{DD}

Publicación: Trop. Subtrop. Pflanzenwelt 66: 33, t. 20. 1988.

Colección tipo: W. Rauh \& K. Von Bismarck 53566

Herbarios: HEID.

Nombre común: D esconocido.

Registro departamental: AM, MD.

Regiones Ecológicas: BMHP, BHA; $1000 \mathrm{~m}$.

SINANPE: PNM

Herbarios peruanos: USM (1).

Observaciones: Esta hierba terrestre es conocida de dos localidades aisladas, por más de $500 \mathrm{~km}$ en línea recta. El ejemplar tipo, probablemente, fue recolectado en la cuenca del Utcubamba.

82. Pitcairnia vargasiana L.B. Sm.

$$
\text { CR, Bla }
$$

Publicación: Phytologia 10(1): 32, t. 1, f. 4, 5. 1964.

Colección tipo: C. Vargas C. 14716

Hemarios: US; CUZ!.

Nombre común: D esconocido.

Registro departamental: CU.

Regiones Ecológicas: BMHM; $2000 \mathrm{~m}$.

SINAN PE: Sin registro.

Herbanios peruanos: CUZ (isotipo).
Observaciones: Hierba terrestre conocida sólo de la colección tipo, una planta recolectada en 1963, de laderas rocosas, en una localidad no precisada, en la cuenca del Paucartambo. Probablemente incendios intencionales de los matorrales podría afectar esas poblaciones.

\section{Pitcairnia wolfei L.B. Sm.}

\section{CR, Bla}

Publicación: Phytologia 21(2): 91-92, t. 3, f. 4, 5. 1971

Colección tipo: F. Wolfe \& T.R. Dudley 12404

Hemarios: NA, US.

Nombre común: D esconocido.

Registro departamental: HU.

Regiones Ecológicas: BMHM; $1535 \mathrm{~m}$.

SINAN PE: Sin registro.

Herbarios peruanos: Ninguno.

Observaciones: Hierba terrestre conocida solo del material tipo, una planta recolectada en 1969 ,de una localidad hoy en la Reserva Comunal El Sira, en la cuenca del Pachitea.

\section{Pitcairnia yaupi-bajaensis Rauh}

Publicación: Trop. Subtrop. Pflanzenwelt 43(14): 46-50, f. 28-30. 1983.

Colección tipo: W. Rauh 25718

Herbarios: HEID.

Nombre común: D esconocido.

Registro departamental: PA.

Regiones Ecológicas: BMHM; $1800 \mathrm{~m}$.

SINANPE: Sin registro.

Herbarios peruanos: Ninguno.

Observaciones: Este taxón fue considerado por Brako \& Zarucchi (1993) como un endemismo; sin embargo, no ha sido posible evaluarlo, ni asignarle una categoría.

85. Puya adscendens L.B. Sm.

\section{CR, Blab(iii)}

Publicación: Phytologia 16(2): 76- 77, t.1, f. 17, 18. 1968.

Colección tipo: A. Sagástegui A. 6073

Herbarios: US; $\underline{\text { HUT. }}$.

Nombre común: D esconocido.

Registro departamental: AM.

Regiones Ecológicas: BMHM; $2300 \mathrm{~m}$.

SINAN PE: Sin registro.

Herbarios penuanos: HUT (holotipo citado).

Obsenvaciones: Hierba conocida solamente de una localidad, en la cuenca del Marañón, en Cerros Calla Calla. Esta especie no ha vuelto a ser recolectada desde 1965, siendo de preocupación la modificación de los ambientes en su localidad original.

86. Puya angulonis L.B. Sm.

\section{NT}

Publicación: Phytologia 6(5): 260, t. 1, f. 13-15. 1958.

Colección tipo: N. Angulo 1708

Herbarios: US; $\underline{\text { HUT. }}$.

Nombre común: Quemason.

Registro departamental: CA, LL.

Regiones Ecológicas: MA, PAR; 3070$4000 \mathrm{~m}$.

SINAN PE: Sin registro.

Herbarios peruanos: HAO (2), HUT (isotipo citado+1), USM (2). 
Observaciones: Esta especie se conoce de varias localidades, principalmente, en el norte del país, si bien un ejemplar disyunto en el sur del país sugiere que su área de extensión sea mayor. Por su hábitat generalmente inaccesible esta especie sobrevive aparentemente fuera de la influencia directa del pastoreo intensivo.

\section{Puya angusta L.B. Sm.}

\section{EN, Bla}

Publicación: Publ. Mus. Hist. Nat. «Javier Prado», Ser. B, Botanica 16: 1-2, figs. 12. [oct 1963] 1964.

Colección tipo: A. Sagástegui A. 3880

Herbarios: US.

Nombre común: D esconocido.

Registro departamental: AN, CA.

Regiones Ecológicas: MA, PSH, AA; 2850- $4700 \mathrm{~m}$.

SINANPE: PNH

Herbarios peruanos: CPUN (1), USM (6).

Observaciones: Hierba terrestre conocida del centro del país. Las poblaciones de esta especie se conocen del Parque Nacional Huascarán y de sus alrededores.

\section{Puya araneosa L.B. Sm.}

\section{EN, Blab(iii)}

Publicación: Phytologia 5(2): 48, t. 6, f. 7-9. 1954.

Colección tipo: E. Cerrate 2049

Herbarios: US; USM!

Nombre común: Cardo, Q ueshque.

Registro departamental: HV, LI.

Regiones Ecológicas: PSH; $4000 \mathrm{~m}$.

SINAN PE: Sin registro.

Hemarios penuanos: USM (isotipo).

Observaciones: Esta especie se conoce del centro del país. Las localidades conocidas están naturalmente fragmentadas. Amenazas potenciales provienen de los incendios intencionales.

\section{Puya argentea L.B. Sm.}

$$
\text { EN, Bla }
$$

Publicación: Phytologia 5(8): 397-398, t. 1, f. 5, 6. 1956.

Colección tipo: W. Rauh \& G. Hirsch P-2075 Herbarios: US.

Nombre común: D esconocido.

Registro departamental: AN.

Regiones Ecológicas: MA; $3000 \mathrm{~m}$.

SINAN PE: PNH

Hembarios peruanos: Ninguno.

Observaciones: Esta especie se conoce de una localidad, ubicada hoy en el Parque Nacional Huascarán. No ha vuelto aparentemente a ser recolectada desde 1954.

\section{Puya casmichensis L.B. Sm.}

$$
\text { EN, Bla }
$$

Publicación: Publ. Mus. Hist. Nat. «Javier Prado», Ser. B, Botanica 16: 2-3, figs. 35. 1964.

Colección tipo: A. López M. et al. 3957

Herbarios: US; HUT!.

Nombre común: Desconocido.

Registro departamental: LL.

Regiones Ecológicas: MA; $1800 \mathrm{~m}$.

SINANPE: Sin registro.

Herbanios penuanos: HUT (isotipo).
Observaciones: Esta especie se conoce solamente de la colección tipo, una planta recolectada en la vertiente occidental, en laderas rocosas con vegetación semixérica. Este tipo de ambientes son escasamente herborizados y ello tal vez contribuya a lo poco que se la conoce.

\section{Puya cerrateana L.B. Sm.}

$$
\text { EN, Bla }
$$

Publicación: Contr. U.S. Natl. Herb. 29(11): 533, f. 8. 1954.

Colección tipo: E. Cerrate 369

Herbarios: US; USM!.

Nombre común: Tuyu, achupalla.

Registro departamental: AN.

Regiones Ecológicas: PSH, AA; 3650$4300 \mathrm{~m}$.

SINANPE: PNH

Hemarios penuanos: USM (isotipo).

Observaciones: Hierba terrestre conocida de dos localidades, en el departamento de Ancash. El ejemplar tipo proviene de la cuenca alta del Pativilca.

\section{Puya commixta L.B.Sm.}

\section{DD}

Publicación: Phytologia 8(9): 501, t. 2, f. 9-10. 1963.

Colección tipo: R.D. Metcalf \& T.H.

Goodspeed 30591

Herbarios: UC, US.

Nombre común: D esconocido.

Registro departamental: PU.

Regiones Ecológicas: BMHM; 1800$2100 \mathrm{~m}$.

SINANPE: Sin registro.

Herbarios peruanos: Ninguno.

Observaciones: Esta especie se conoce solamente de una localidad, en el sur del país. No ha vuelto a ser recolectada desde 1942. Se desconoce el estado de sus poblaciones.

\section{Puya coriacea L.B. Sm.}

\section{VU, Bla}

Publicación: Phytologia 13(2): 142, t. 6 , f. 8-9. 1966.

Colección tipo: P.C. Hutchison et al. 6170

Herbarios: F, MO, NY, UC, US; USM!.

Nombre común: D esconocido.

Registro departamental: CA, LL.

Regiones Ecológicas: PAR; 3630-3650 m. SINANPE: Sin registro.

Herbarios peruanos: CPUN (2), USM (isotipo).

Observaciones: Hierba conocida de unas pocas localidades dispersas, en la cuenca del Marañón, donde ocupaáreas húmedas de la jalca. Esta especie ha sido recolectada en diferentes años desde 1964. Al igual que otras especies de la región Páramo, los incendios intencionales y la actividad minera podrían ser amenazas a sus poblaciones. 


\section{Puya cylindrica Mez}

$$
\text { EN, B1ab(iii) }
$$

Publicación: Repert. Spec. Nov. Regni Veg. 16: 66. 1919.

Colección tipo: A. Weberbauer 6873

Herbarios: B, F, GH; MOL!.

Nombre común: D esconocido.

Registro departamental: AR, CU.

Regiones Ecológicas: MA; 2500- $2600 \mathrm{~m}$.

SINANPE: RPSC

Herbarios penuanos: MOL (isotipo).

Observaciones: Hierba terrestre que se conoce de sólo dos poblaciones aisladas, en ambas vertientes, en áreas sujetas a pastoreo y agricultura, en el sur del país. Fue descrita de una planta recolectada en la cuenca del Cotahuasi, en 1914, hoy una Reserva Paisajística.

\section{Puya densiflora Harms}

Publicación: Notizbl. Bot. Gart. BerlinDahlem 10: 791. 1929.

Colección tipo: F. Herrera 1954

Herbarios: B.

Nombre común: D esconocido.

Registro departamental: AP, AR, CU.

Regiones Ecológicas: MA; 2200-3200 m.

SINAN PE: Sin registro.

Herbarios peruanos: CUZ (4).

Observaciones: Este taxón fue considerado por Brako \& Zarucchi (1993) como un endemismo; sin embargo, no ha sido posible evaluarlo, ni asignarle una categoría.

\section{Puya depauperata L.B. Sm.}

Publicación: Contr. Gary Herb. 98:10, t. 3, f. 10, 11. 1932.

Colección tipo: J.F. Macbride \& W. Featherstone 1339

Herbarios: F.

Nombre común: D esconocido.

Registro departamental: JU.

Regiones Ecológicas: MA; $2400 \mathrm{~m}$.

SINAN PE: Sin registro.

Herbarios peruanos: Ninguno.

Observaciones: Este taxón fue considerado por Brako \& Zarucchi (1993) como un endemismo; sin embargo, no ha sido posible evaluarlo, ni asignarle una categoría.

\section{Puya dolichostrobila Harms}

\section{EN, Bla}

Publicación: Notizbl. Bot. Gart. BerlinD ahlem 10: 215. 1928.

Colección tipo: A. Weberbauer 6981

Herbarios: B, F; MOL!

Nombre común: D esconocido.

Registro departamental: AM, LL.

Regiones Ecológicas: MDE; 1400- 2000 m.

SINANPE: Sin registro.

Herbarios peruanos: MOL (isotipo), USM (isotipo).

Observaciones: Hierba terrestre conocida sólo de dos localidades. El ejemplar tipo fue recolectado en ambientes xerofíticos del valle del río Chicama, en la vertiente del Pacífico. Ha sido registrada en la cuenca del Marañón.

\section{Puya ferox Mez}

\section{CR, Bla}

Publicación: Bull. Herb. Boissier, ser. 2, 4:632. 1904.

Colección tipo: A. Weberbauer 1344

Hembarios: B, WRSL.

Nombre común: D esconocido.

Registro departamental: PU.

Regiones Ecológicas: BMHM; 2200$2400 \mathrm{~m}$.

SINAN PE: Sin registro.

Herbarios peruanos: Ninguno.

Observaciones: Esta especie se conoce del único ejemplar procedente de Puno. Esta planta fue recolectada en 1902, en ambientes rocosos, en matorral arbustivo. La zona ha sido herbonizada varias veces.

99. Puya ferreyrae L.B. Sm.

\section{EN, Bla}

Publicación: Publ. Mus. Hist. Nat. «Javier Prado», Ser. B. Bot. 13: 1-3, figs. 1-3. 1962. Colección tipo: R. Ferreyra 14096

Herbarios: US; USM!.

Nombre común: Achupaya.

Registro departamental: AN, LL.

Regiones Ecológicas: MA; 1500-3695 m. SINANPE: Sin registro.

Herbarios penuanos: USM (holotipo+1).

Observaciones: Hierba conocida de dos localidades, en las cuencas altas del Moche y Tablachaca, vertiente del Pacífico. A parentemente una población grande existe en la cuenca del Marañón (Asunción Cano, com. pers.).

\section{Puya fulgens L.B. Sm.}

\section{CR, Bla}

Publicación: Phytologia 9(4): 249-250, t. 2, f. 14-16. 1963.

Colección tipo: J.J. Wurdack 1458

Herbanios: NY, US; USM!.

Nombre común: D esconocido.

Registro departamental: AM.

Regiones Ecológicas: BMHM; 2850$2900 \mathrm{~m}$.

SINAN PE: Sin registro.

Herbarios peruanos: USM (isotipo).

Observaciones: Esta especie se conoce solamente de una localidad, en ambientes abiertos, donde era localmente abundante, pero no ha vuelto a ser recolectada desde 1962.

\section{Puya gendae W. Weber}

\section{DD}

Publicación: Cat. Herb. Lips. Pl. Neotrop. 2: 41.1984.

Colección tipo: P. Gutte et al. 508

Herbarios: LZ, WEB; $\underline{\text { SMF. }}$

Nombre común: D esconocido.

Registro departamental: LI.

Regiones Ecológicas: MA; $2500 \mathrm{~m}$.

SINANPE: Sin registro.

Herbarios penuanos: SMF (isotipo citado).

Observaciones: Esta especie es conocida aparentemente sólo de la colección tipo, una planta recolectada en la cuenca del Chillón, en 1973. 


\section{Puya gend-muelleriW. Weber}

Publicación: Cat. Herb. Lips. Plantae Peruvianae 2: 42. 1984.

Colección tipo: P. Gutte \& G. Müller 8890

Hemarios: LZ.

Nombre común: D esconocido.

Registro departamental: CA.

Regiones Ecológicas: PAR; $3800 \mathrm{~m}$.

SINANPE: Sin registro.

Herbarios peruanos: Ninguno.

Observaciones: Este taxón fue considerado por Brako \& Zarucchi (1993) como un endemismo; sin embargo, no ha sido posible evaluarlo, ni asignarle una categoría.

103. Puya glandulosa L.B. Sm.

$$
\text { CR, Bla }
$$

Publicación: Phytologia 13(2): 142-143, t. 6, f. 10, 11. 1966.

Colección tipo: P.C. Hutchison et al. 6123

Herbarios: F, K, MO, NY, UC, US.

Nombre común: D esconocido.

Registro departamental: LL.

Regiones Ecológicas: MA; $2290 \mathrm{~m}$.

SINANPE: Sin registro.

Herbarios peruanos: Ninguno.

Observaciones: Esta hierba se conoce sólo de la localidad tipo, ubicada en la vertiente del Pacífico, cuenca alta del Moche; al parecer, no ha vuelto a ser recolectada desde 1964.

104. Puya gracilis L.B. Sm.

Publicación: Contr. Gray Herb. 98: 11, t. 3, f. 1, 13. 1932.

Colección tipo: A. Weberbauer 6474

Herbarios: F; MOL!.

Nombre común: D esconocido.

Registro departamental: $\mathrm{HU}, \mathrm{HV}$.

Regiones Ecológicas: MA; 1500- 2100

$\mathrm{m}$

SINANPE: Sin registro.

Herbarios peruanos: MOL (isotipo).

Observaciones: Este taxón fue considerado por Brako \& Zarucchi (1993) como un endemismo; sin embargo, no ha sido posible evaluarlo, ni asignarle una categoría.

\section{Puya grandidens Mez}

Publicación: Repert. Spec. Nov. Regni Veg. 3: 10- 11. 1906

Colección tipo: A. Weberbauer 2738

Herbarios: B; MOL!.

Nombre común: D esconocido.

Registro departamental: AN.

Regiones Ecológicas: MA; 3000-3200 m.

SINANPE: Sin registro.

Herbarios peruanos: MOL (isotipo).

Observaciones: Este taxón fue considerado por Brako \& Zarucchi (1993) como un endemismo; sin embargo, no ha sido posible evaluarlo, ni asignarle una categoría.
106. Puya gutteana W. Weber

Publicación: Cat. Herb. Lips. Plantae Peruvianae 2: 42. 1984.

Colección tipo: P. Gutte \& G. Gutte 3308

Hemarios: HAL, LZ; SMF.

Nombre común: D esconocido.

Registro departamental: CU.

Regiones Ecológicas: Sin datos; altitud desconocida.

SINAN PE: Sin registro.

Herbarios penuanos: SMF (isotipo citado).

Observaciones: Esta hierba es conocida, al parecer, de la colección tipo. No ha sido posible evaluarla, ni asignarle una categoría.

107. Puya huancavelicae L.B. Sm.

DD

Publicación: Phytologia 7(1): 4-5, t. 1, f. 15, 16. 1959.

Colección tipo: O. Tovar 2124

Henbarios: US.

Nombre común: Jesje.

Registro departamental: HV.

Regiones Ecológicas: MA; 2000-3200 m.

SINAN PE: Sin registro.

Herbarios peruanos: Ninguno.

Observaciones: Esta especie se conoce solamente de una localidad, ubicada en la cuenca del río Mantaro, donde no ha vuelto a ser recolectada desde 1954, probablemente, por lo poco herborizado que es esa parte de Huancavelica.

108. Puya hutchisonii L.B. Sm.

\section{CR, Bla}

Publicación: Phytologia 13(2): 143, t. 6 , f. 12-14. 1966.

Colección tipo: P.C. Hutchison \& J.K. Wright 4380

Herbarios: UC, US; USM!.

Nombre común: D esconocido.

Registro departamental: AN.

Regiones Ecológicas: MA; $2875 \mathrm{~m}$.

SINANPE: Sin registro.

Herbarios penuanos: USM (isotipo).

Observaciones: Hierba terrestre conocida solamente de la colección tipo, una planta recolectada en 1964, en la cuenca del Santa. Aparentemente rara en la localidad de recolecta.

\section{Puya iltisiana L.B. Sm.}

\section{DD}

Publicación: Phytologia 13(2): 143-144, t. 6, f. 15, 16. 1966.

Colección tipo: $\mathrm{H}$. Iltis et al. 613

Herbarios: UC, US, WIS.

Nombre común: D esconocido.

Registro departamental: AP.

Regiones Ecológicas: MA; $2700 \mathrm{~m}$.

SINAN PE: Sin registro.

Herbarios peruanos: Ninguno.

Observaciones: Hierba conocida solamente dela localidad original, en la cuenca del Pachachaca, donde crecía en laderas semixéricas y rocosas. Este tipo de ambientes reciben escasa herborización. Aparentemente no ha vuelto a ser recolectada desde 1962. 


\section{Puya isabellina Mez}

Publicación: Repert. Spec. Nov. Regni Veg. 16: 66. 1919

Colección tipo: A. Weberbauer 4144

Henbarios: B; USM!.

Nombre común: sugar (Ferreyra \& Sanchez 19714 USM)

Registro departamental: AM, CA.

Regiones Ecológicas: MA; $1300 \mathrm{~m}$.

SINANPE: Sin registro.

Herbarios peruanos: USM (isotipo+1).

Observaciones: Este taxón fue considerado por Brako \& Zarucchi (1993) como un endemismo; sin embargo, no ha sido posible evaluarlo, ni asignarle una categoría.

\section{Puya laccata Mez}

Publicación: Repert. Spec. Nov. Regni Veg. 3: 11.1906.

Colección tipo: A. Weberbauer 3376

Herbarios: B, GH.

Nombre común: D esconocido.

Registro departamental: HU.

Regiones Ecológicas: BMHM; 3300$3500 \mathrm{~m}$.

SINAN PE: Sin registro.

Herbarios peruanos: Ninguno.

Observaciones: Este taxón fue considerado por Brako \& Zarucchi (1993) como un endemismo; sin embargo, no ha sido posible evaluarlo, ni asignarle una categoría.

\section{Puya lanuginosa (Ruiz \& Pav.) Schult. f.}

Publicación: Syst. Veg. Fl. Peruv. Chil. 7(2): 1234. 1830.

Colección tipo: H. Ruiz \& J. Pavón 5/ 25

Herbarios:

Nombre común: Mahra.

Registro departamental: HU, JU, PA.

Regiones Ecológicas: MA; altitud desconocida.

SINAN PE: Sin registro.

Hemarios peruanos: Ninguno.

Observaciones: Este taxón fue considerado por Brako \& Zarucchi (1993) como un endemismo; sin embargo, no ha sido posible evaluarlo, ni asignarle una categoría.

113. Puya llatensis L.B. Sm.

Publicación: Contr. G ray Herb. 98: 11, t. 3, f. 14-16. 1932.

Colección tipo: J.F. Macbride \& W.

Featherstone 2300

Henbarios: $F, G H$.

Nombre común: D esconocido.

Registro departamental: HU.

Regiones Ecológicas: MA; $2300 \mathrm{~m}$.

SINAN PE: Sin registro.

Hembarios peruanos: Ninguno.

Observaciones: Este taxón fue considerado por Brako \& Zarucchi (1993) como un endemismo; sin embargo, no ha sido posible evaluarlo, ni asignarle una categoría.

\section{Puya longisepala Mez}

Publicación: Bull. Herb. Boissier, ser. 2, 4: 269. 1904.

Colección tipo: A. Weberbauer 550

Herbarios: B; MOL!.

Nombre común: D esconocido.

Registro departamental: PU.

Regiones Ecológicas: BMHM; $2100 \mathrm{~m}$.

SINANPE: Sin registro.

Hemarios penuanos: MOL (isotipo).

Observaciones: Este taxón fue considerado por Brako \& Zarucchi (1993) como un endemismo; sin embargo, no ha sido posible evaluarlo, ni asignarle una categoría.

\section{Puya longistyla Mez}

Publicación: Repert. Spec. Nov. Regni Veg. 3: 12-13. 1906.

Colección tipo: A. Weberbauer 4916

Hemarios: B.

Nombre común: D esconocido.

Registro departamental: CU.

Regiones Ecológicas: MA; 3000-3100 m.

SINANPE: Sin registro.

Herbarios penuanos: $\operatorname{CUZ}(2)$.

Observaciones: Este taxón fue considerado por Brako \& Zarucchi (1993) como un endemismo; sin embargo, no ha sido posible evaluarlo, ni asignarle una categoría.

116. Puya lopezii L.B. Sm.

Publicación: Phytologia 8(9): 501- 502, t. 2, f. 11, 12. 1963.

Colección tipo: A. López M. \& A. Sagástegui A. 3549

Herbarios: US.

Nombre común: Desconocido.

Registro departamental: LL.

Regiones Ecológicas: MA; $2300 \mathrm{~m}$.

SINANPE: Sin registro.

Hembarios peruanos: Ninguno.

Observaciones: El material tipo no se encuentra en el herbario HUT. No ha sido posible evaluarla, ni asignarle una categoría.

\section{Puya macbridei L.B. Sm. subsp.macbridei}

$$
\text { EN, B1a }
$$

\section{Publicación:}

Colección tipo: J.F. Macbride \& W. Featherstone 2516

Hemarios: $F$.

Nombre común: D esconocido.

Registro departamental: AN.

Regiones Ecológicas: MA, PSH; 2500$3000 \mathrm{~m}$.

SINAN PE: PNH

Herbarios peruanos: Ninguno.

Observaciones: Este taxón se conoce solamente de dos localidades, pero probablemente, otras en el Parque Nacional Huascarán incluyan poblaciones de esta especie. Por su hábitat confinado a paredes rocosas no se conocen de amenazas directas. 
118. Puya macbridei L.B. Sm. subsp.yungayensisW. Weber

Publicación: Cat. Herb. Lips. Plantae Peruvianae 2: 44. 1984.

Colección tipo: P. Gutte \& M. Chanco 9687

Herbarios: LZ.

Nombre común: D esconocido.

Registro departamental: AN.

Regiones Ecológicas: Sin datos; altitud desconocida.

SINAN PE: Sin registro.

Hembarios peruanos: Ninguno.

Observaciones: Hierba conocida solamente dela colección original. No ha sido posible evaluarla, ni asignarle una categoría.

\section{Puya macrura Mez}

\section{DD}

Publicación: Repert. Spec. Nov. Regni Veg. 3: 13-14. 1906.

Colección tipo: A. Weberbauer 3022

Herbarios: B; MOL!.

Nombre común: Muckchache, cashcaypahueta

Registro departamental: AN, LL.

Regiones Ecológicas: MA; 1900-3300 m.

SINANPE: Sin registro.

Herbarios penuanos: MOL (isotipo).

Observaciones: Especie herbácea conocida de varias localidades, principalmente en la cuenca del Santa. Se desconoce el estado de sus poblaciones.

120. Puya mariae L.B. Sm.

$$
\text { EN, Bla }
$$

Publicación: Phytologia 9(4): 250, t. 2, f. 17, 18. 1963.

Colección tipo: J.J. Wurdack 602

Herbarios: NY, US; USM.

Nombre común: D esconocido.

Registro departamental: AM.

Regiones Ecológicas: BMHM; 1800$2400 \mathrm{~m}$.

SINANPE: Sin registro.

Herbarios peruanos: HUT (1), USM (isotipo citado).

Observaciones: Esta especie se conoce de los alrededores de Chachapoyas, donde, al parecer, es localmente abundante. No se conoce de amenazas a los ambientes donde se hallan poblaciones de esta planta. Sin embargo, no ha vuelto a ser recolectada desde 1964.

121. Puya medica L.B. Sm.

Publicación: Phytologia 4(4): 216-217, t. 2, f. 1, 2. 1953.

Colección tipo: E. Cerrate 1333

Herbarios: US; USM!.

Nombre común: achupalla blanca

Registro departamental: AN, CA, LL.

Regiones Ecológicas: MA; 2800-2950 m.

SINAN PE: Sin registro.

Herbarios peruanos: USM (isotipo).

Observaciones: Este taxón fue considerado por Brako \& Zarucchi (1993) como un endemismo; sin embargo, no ha sido posible evaluarlo, ni asignarle una categoría.
122. Puya membranacea L.B. Sm.

EN, Bla

Publicación: Phytologia 7(8): 421, t. 1, f.

14, 15. 1961.

Colección tipo: J. West 7032

Herbarios: UC.

Nombre común: D esconocido.

Registro departamental: $\mathrm{CU}$.

Regiones Ecológicas: $\mathrm{BPM}, \mathrm{BMHM}$; 3360-3380 m.

SINAN PE: PNM

Herbarios penuanos: USM (1).

Observaciones: Esta especie se conoce, al parecer, de unas pocas colecciones, procedentes de una localidad, en los límites occidentales del Parque Nacional Manu. Fue descrita de una planta creciendo sobre rocas, en la década de 1930.

\section{Puya mima L.B. Sm. \& Read}

Publicación: Phytologia 41(5): 329. 1979. Colección tipo: P.C. Hutchison 18109

Herbarios: US.

Nombre común: D esconocido.

Registro departamental: CA.

Regiones Ecológicas: MDE, MA; 1000$2700 \mathrm{~m}$.

SINANPE: Sin registro.

Hemarios penuanos: CPUN (2), HAO (1).

Observaciones: Solamente conocida de Cajamarca. Vertiente occidental. No ha sido posible evaluarla, ni asignarle una categoría.

\section{Puya mitis Mez}

\section{EN, Bla}

Publicación: Repert. Spec. Nov. Regni Veg. 3: 10. 1906.

Colección tipo: A. Weberbauer 2094

Herbarios: B; MOL!

Nombre común: Desconocido.

Registro departamental: AM, JU.

Regiones Ecológicas: BPM, BMHM; 2600-3000 m.

SINAN PE: Sin registro.

Hemarios penuanos: MOL(isotipo).

Observaciones: Esta especie fue descrita de una planta recolectada en 1903, de ambientes ecotonales bosque-pajonal en la zona de Huacapistana, en la cuenca del Palca. Se conoce de ambientes rocosos en áreas con fuerte impacto de incendios y deforestación. No hay colecciones recientes.

\section{Puya nigrescens L.B. Sm.}

\section{CR, Bla}

Publicación: Publ. Mus. Hist. Nat. «Javier Prado», Ser. B. Bot. 16: 4-5, figs. 6-8. [oct 1963] 1964.

Colección tipo: E. Cerrate 4103

Herbarios: US; USM!.

Nombre común: Tuyu.

Registro departamental: AN.

Regiones Ecológicas: MA; 3600 m.

SINAN PE: Sin registro.

Herbarios peruanos: USM (isotipo). 
Observaciones: Hierba terrestre conocida solamente de la cuenca del Pativilca. La localidad tipo se ubica en una zona que está sujeta a incendios intencionales ocasionales. Cambios climáticos podrían afectar las comunidades vegetales de farallones rocosos que dependen de la precipitación estacional.

\section{Puya oxyantha Mez}

\section{EN, Bla}

Publicación: Bull. Herb. Boissier, ser. 2, 4: 631. 1904.

Colección tipo: A. Weberbauer 1058

Herbarios: B.

Nombre común: D esconocido.

Registro departamental: PU.

Regiones Ecológicas: PSH; 2400-2500 $\mathrm{m}$.

SINANPE: Sin registro.

Herbarios peruanos: USM (2).

Observaciones: Hierba terrestre conocida de la cuenca alta del Inambari. El ejemplar tipo fue recolectado en 1902. Esta especie ha sido recolectada en 1973. Probablemente sus poblaciones estén expuestas a la quema asociada al pastoreo intensivo.

127. Puya pitcairnioides L.B. Sm.

Publicación: Publ. Mus. Hist. Nat. «Javier Prado», Ser. B. Bot. 16: 5. 1964.

Colección tipo: A. Weberbauer 4268

Herbarios: B.

Nombre común: D esconocido.

Registro departamental: AM.

Regiones Ecológicas: BS; 3200- 3500 m.

SINAN PE: Sin registro.

Herbarios peruanos: Ninguno.

Observaciones: Este taxón fue considerado por Brako \& Zarucchi (1993) como un endemismo; sin embargo, no ha sido posible evaluarlo, ni asignarle una categoría.

128. Puya ponderosa L.B.Sm.

\section{DD}

Publicación: Phytologia 13(2): 144-145.

1966.

Colección tipo: $\mathrm{H}$. Iltis et al. 445

Herbarios: US, WIS.

Nombre común: D esconocido.

Registro departamental: AY.

Regiones Ecológicas: $\mathrm{PSH} ; 3800 \mathrm{~m}$.

SINAN PE: RNPG

Herbarios peruanos: Ninguno.

Observaciones: Esta especie fue descrita de una planta recolectada en una localidad, en la cuenca alta del Acaní, en el suroeste de Ayacucho. Recientemente, un ejemplar de Cajamarca se ha atribuido a esta especie (ver TROPICOS) procedente de la cuenca del Marañón. Aquí se la acepta solamente para Ayacucho, pero se necesita mayor herborización delas laderas semixéricas del país para aclarar la situación de esta especie.
129. Puya pratensis L.B. Sm.

VU, Bla

Publicación: Phytologia 4(4): 217, t. 2, f. 3, 4. 1953.

Colección tipo: R. Ferreyra 8580

Herbarios: USM!.

Nombre común: D esconocido.

Registro departamental: CA, LL.

Regiones Ecológicas: PSH, PAR; 3100$3500 \mathrm{~m}$.

SINAN PE: Sin registro.

Herbarios peruanos: HUT (2), USM (holotipo).

Observaciones: Esta especie se conoce de las jalcas, en el norte del país. La localidad original se encuentra muy cerca de la ciudad de Cajamarca. Esta especie se conoce de tres poblaciones en la serranía de La Libertad.

\section{Puya pseudoeryngioides H. Luther}

\section{CR, Bla}

Publicación: Selbyana 23: 53, f. 7. 2002.

Colección tipo: H. van der Werff et al. 14950

Herbarios: MO, SEL; HUT!.

Nombre común: D esconocido.

Registro departamental: AM.

Regiones Ecológicas: BMHM; altitud desconocida.

SINANPE: Sin registro.

Herbanios penuanos: HUT (isotipo).

Observaciones: Hierba terrestre conocida solamente de la colección tipo, proveniente de un bosque montano, sobre suelos arenosos. Estos tipos de bosques montanos han sido poco herborizados y ello sirva para explicar la ausencia de colecciones adicionales. Probablemente, amenazas a esta especie provienen de incendios intencionales.

\section{Puya pyramidata (Ruiz \& Pav.) Schult. f.}

Publicación: Syst. Veg. 7, pt. 2: 1235. 1830. Colección tipo: H. Ruiz \& J. Pavón s.n. Herbarios: MA.

Nombre común: Achupalla.

Registro departamental: HU, LL.

Regiones Ecológicas: MA, PAR; 3700 m.

SINAN PE: Sin registro.

Herbarios peruanos: Ninguno.

Observaciones: Este taxón fue considerado por Brako \& Zarucchi (1993) como un endemismo; sin embargo, no ha sido posible evaluarlo, ni asignarle una categoría.

132. Puya ramonii L.B. Sm.

Publicación: J. Bromeliad Soc. 40(2): 57. 1990.

Colección tipo: R. Ferreyra 20910

Herbarios: US; USM!.

Nombre común: D esconocido.

Registro departamental: LA.

Regiones Ecológicas: PAR; 3700-3800 m.

SINAN PE: Sin registro.

Henbarios peruanos: USM (isotipo). 
Observaciones: Este taxón fue considerado por Brako \& Zarucchi (1993) como un endemismo; sin embargo, no ha sido posible evaluarlo, ni asignarle una categoría.

\section{Puya ramosa L.B. Sm.}

\section{CR, Bla}

Publicación: Phytologia 9(4): 250-251, t. 3, f. 1, 2. 1963.

Colección tipo: J.J. Wurdack 1600

Herbarios: NY, US.

Nombre común: D esconocido.

Registro departamental: AM. Regiones Ecológicas: BPM; 3200-3500 m.

SINANPE: Sin registro.

Herbarios peruanos: USM?.

Observaciones: Esta planta fue descrita de una población en el norte del país, donde era localmente abundante.; sin embargo, no ha vuelto a ser recolectada desde 1962. La localidad tipo, cerca aD iosan, alberga otros endemismos, por lo que debería ser de interés a botánicos y conservacionistas.

\section{Puya rauhii L.B.Sm.}

\section{EN, Bla}

Publicación: Phytologia 5(8): 398, t. 1, f. 7, 8. 1956.

Colección tipo: W. Rauh \& G. Hirsch P2022

Herbarios: US.

Nombre común: Desconocido.

Registro departamental: AN.

Regiones Ecológicas: PSH; 3900 m.

SINANPE: PNH

Herbarios peruanos: Ninguno.

Observaciones: Esta especie se conoce solamente de una localidad, Llanganuco, una de las zonas más visitadas y herborizadas, el Parque Nacional Huascarán; sin embargo, al parecer, no ha vuelto a ser recolectada desde 1954.

\section{Puya reflexiflora Mez}

Publicación: Repert. Spec. Nov. Regni Veg. 16: 66. 1919

Colección tipo: A. Weberbauer 3148

Herbarios: B; MOL!.

Nombre común: D esconocido.

Registro departamental: AN, CA.

Regiones Ecológicas: MA, PSH; 3800$3900 \mathrm{~m}$.

SINANPE: Sin registro.

Herbarios peruanos: MOL (isotipo), USM (1).

Observaciones: Este taxón fue considerado por Brako \& Zarucchi (1993) como un endemismo; sin embargo, no ha sido posible evaluarlo, ni asignarle una categoría.
136. Puya robin-fosteri G.S. Varad. \& H. Luther

CR, Blab(iii)

Publicación: Selbyana 16(2): 235, f. 2 ad. 1995.

Colección tipo: R.B. Foster 9062

Herbarios: F, SEL.

Nombre común: D esconocido.

Registro departamental: PA.

Regiones Ecológicas: BMHM; 2700$2800 \mathrm{~m}$.

SINAN PE: Sin registro.

Hembarios penuanos: USM (1).

Observaciones: Esta es una especie conocida solamente de una localidad, donde es localmente abundante. Robin Foster, el recolector de esta planta, comenta la agrupación compacta que forma esta planta. La zona está afectada por incendios intencionales que elimina el substrato de Sphagnum .

\section{Puya roezlii E. Morren}

Publicación: Belgique Hort. 35: 80. 1885.

Colección tipo: Roezl s.n.

Hembarios: LG.

Nombre común: Kkeski

Registro departamental: AN, AP, LI.

Regiones Ecológicas: MA; 2500- 2800 m.

SINANPE: Sin registro.

Herbarios penuanos: CUZ (1), USM (4).

Observaciones: Este taxón fue considerado por Brako \& Zarucchi (1993) como un endemismo; sin embargo, no ha sido posible evaluarlo, ni asignarle una categoría.

\section{Puya sagasteguii L.B. Sm.}

\section{DD}

Publicación: Phytologia 8(9): 502, t. 2, f. 13, 14. 1963.

Colección tipo: A. López M. \& A. Sagástegui A. 3549

Henbarios: US.

Nombre común: D esconocido.

Registro departamental: LL.

Regiones Ecológicas: BS; $2500 \mathrm{~m}$.

SINANPE: Sin registro.

Herbarios peruanos: Ninguno.

Observaciones: Hierba terrestre descrita de una planta recolectada en 1961, de la cuenca del Marañón, de ambientes xéricos. Se desconoce el estado de sus poblaciones.

139. Puya simulans L.B. Sm.

\section{CR, Bla}

Publicación: Phytologia 16(6): 461, t.1, f. 9. 1968.

Colección tipo: A. López M. \& A. Sagástegui A. 2815

Herbarios: US; HUT!

Nombre común: D esconocido.

Registro departamental: LL.

Regiones Ecológicas: MA; 3000-3500 m.

SINANPE: Sin registro.

Herbarios peruanos: HUT (isotipo). 
Observaciones: Hierba conocida de laderas expuestas, en la jalca de La Libertad. No ha vuelto a ser recolectada desde 1958. Probablemente incendios intencionales afecten sus poblaciones.

140. Puya stipitata L.B. Sm.

Publicación: Contr. Gray Herb. 98: 13, t. 4, f. 5, 6. 1932.

Colección tipo: J.F. Macbride 3436

Herbarios: $F$.

Nombre común: D esconocido.

Registro departamental: HU.

Regiones Ecológicas: BMHM; altitud desconocida.

SINANPE: Sin registro.

Herbarios peruanos: Ninguno.

Observaciones: Este taxón fue considerado por Brako \& Zarucchi (1993) como un endemismo; sin embargo, no ha sido posible evaluarlo, ni asignarle una categoría.

\section{Puya strobilantha Mez}

Publicación: Repert. Spec. Nov. Regni Veg. 3: 13. 1906.

Colección tipo: A. Weberbauer 2050

Herbarios: $B$.

Nombre común: D esconocido.

Registro departamental: JU.

Regiones Ecológicas: BMHM; 2000$2100 \mathrm{~m}$.

SINAN PE: Sin registro.

Herbarios peruanos: Ninguno.

Observaciones: Este taxón fue considerado por Brako \& Zarucchi (1993) como un endemismo; sin embargo, no ha sido posible evaluarlo, ni asignarle una categoría.

\section{Puya textoragricolae W. Weber}

\section{DD}

Publicación: Feddes Repert. 97: 101. 1986.

Colección tipo: A. Weberbauer 570

Herbarios: B; MOL!.

Nombre común: D esconocido.

Registro departamental: PU.

Regiones Ecológicas: BMHM; $2100 \mathrm{~m}$.

SINAN PE: Sin registro.

Herbarios penuanos: MOL (isotipo).

Observaciones: Esta especiees conocida, al parecer, sólo dela colección tipo, unaplantarecolectadaen 1902, en el suronientedel país. Lalocalidad se halla en una subcuenca del Inambani, una zona al oeste del Parque Nacional Bahuaja-Sonene. No se conoce el estatus de sus poblaciones, aunque se sabe que a la altitud donde crecía esta planta, sus poblaciones podńan estar afectadas por las actividades agnícolas.

143. Puya tovariana L.B. Sm.

$$
\text { CR, Bla }
$$

Publicación: Phytologia 5(2): 48-49, t. 7., f.1, 2. 1954.

Colección tipo: E. Cerrate \& O. Tovar 1831

Herbarios: US; USM!.

Nombre común: D esconocido.

Registro departamental: LI.

Regiones Ecológicas: MA; 3180 m.

SINAN PE: Sin registro.

Herbarios peruanos: USM (isotipo).
Observaciones: Esta especie se conoce solamente de una localidad en la cuenca alta del Rímac, donde no ha vuelto a ser recolectada desde 1954. Al igual que otras especies en el género esto se deba al reto en recolectar estas plantas. Amenazas potenciales se atribuyen a los incendios intencionales.

\section{Puya tyleriana Sagást., Zapata \& M.0. Dillon}

\section{NE}

Publicación: Amaldoa 11(2): 30, 33, f. 1. 2004. Colección tipo: A. Sagástegui A. \& M. Zapata 17095

Herbarios: BM, F, NY, US; $\mathrm{HAO}$.

Nombre común: D esconocido.

Registro departamental: AN.

Regiones Ecológicas: MA; altitud desconocida.

SINAN PE: Sin registro.

Herbarios peruanos: HAO (holotipo).

Observaciones: Hierba conocida solamente de la colección tipo, proveniente de una subcuenca del Santa, al norte de la Cordillera Blanca y recolectada en 2002.

\section{Puya vargasiana L.B. Sm.}

Publicación: Phytologia 8(5): 227-228, t.2, f. 9, 10. 1962.

Colección tipo: C. Vargas C. 7558

Hembarios: GH, LIL.

Nombre común: D esconocido.

Registro departamental: CU.

Regiones Ecológicas: Sin datos; altitud desconocida.

SINAN PE: Sin registro.

Henbarios penuanos: CUZ?.

Observaciones: Este taxón fue considerado por Brako \& Zarucchi (1993) como un endemismo; sin embargo, no ha sido posible evaluarlo, ni asignarle una categoría.

\section{Puya werneriana Read \& L.B. Sm.}

Publicación: Trop. Subtrop. Pflanzenwelt 58(18): 5, f. 1-2.. 1986.

Colección tipo: W. Rauh 25891

Herbarios: HEID.

Nombre común: D esconocido.

Registro departamental: JU.

Regiones Ecológicas: PSH; 3900 m.

SINAN PE: Sin registro.

Herbarios peruanos: Ninguno.

Observaciones: Este taxón fue considerado por Brako \& Zarucchi (1993) como un endemismo; sin embargo, no ha sido posible evaluarlo, ni asignarle una categoría.

\section{Puya wrightii L.B. Sm.}

Publicación: Phytologia 13(2): 145, t. 6, f. 21, 22. 1966.

Colección tipo: P.C. Hutchison \& J.K. Wright 3560

Hembarios: MICH, UC, US.

Nombre común: D esconocido.

Registro departamental: AM, CA.

Regiones Ecológicas: BS; 380- $1000 \mathrm{~m}$.

SINANPE: Sin registro.

Herbarios peruanos: USM (1). 
Observaciones: Hierba conocida de la cuenca del Chamaya y Marañón, de laderas rocosas y xéricas; no ha sido posible evaluarla, ni asignarle una categoría.

\section{Puya wurdackii L.B. Sm.}

$$
\text { CR, Bla }
$$

Publicación: Phytologia 9(4): 251, t. 3, f. 3, 4. 1963.

Colección tipo: J.J. Wurdack 1066

Herbarios: NY, US.

Nombre común: D esconocido.

Registro departamental: AM.

Regiones Ecológicas: BMHM; 2300$2400 \mathrm{~m}$.

SINAN PE: Sin registro.

Herbarios peruanos: Ninguno.

Observaciones: Especie descrita de un ejemplar recolectado en pajonales, de la cuenca alta del Utcubamba, donde era localmente frecuente. No ha vuelto a ser recolectada desde 1962.

\section{Racinaea cuspidata (L.B. Sm.) M.A. Spencer \& L.B.}

Sm.

\section{EN, Bla}

Publicación: Phytologia 74(2): 153. 1993.

Colección tipo: J.J. Wurdack 1457

Herbarios: NY, US.

Nombre común: D esconocido.

Registro departamental: AM.

Regiones Ecológicas: BPM; 2850-3400 m.

SINAN PE: Sin registro.

Herbarios peruanos: Ninguno.

Observaciones: Hierba epífita conocida de bosques pluviales montanos, en el nor-oriente del país. Las tres poblaciones conocidas aparentemente proceden de la cuenca del Utcubamba.

\section{Racinaea kallianthaJ.R. Grant}

Publicación: Phytologia 76(4): 286. 1994.

Colección tipo: A. Sagástegui A. 10210

Herbarios: SE L.

Nombre común: Desconocido.

Registro departamental: PI.

Regiones Ecológicas: MA; $2400 \mathrm{~m}$.

SINANPE: Sin registro.

Herbarios peruanos: Ninguno.

Observaciones: Este taxón fue descrito posterior a Brako \& Zarucchi (1993); no ha sido posible evaluarlo, ni asignarle una categona.

\section{Racinaea lymansmithianaJ.R. Grant}

Publicación: Phytologia 76(4): 286, 288. 1994. Colección tipo: A. Cano 1449

Herbarios: US.

Nombre común: D esconocido.

Registro departamental: PI.

Regiones Ecológicas: MA; $2950 \mathrm{~m}$.

SINANPE: Sin registro.

Herbarios peruanos: Ninguno.

Observaciones: Este taxón fue descrito posterior a Brako \& Zarucchi (1993); no ha sido posible evaluarlo, ni asignarle una categoría.
152. Tillandsia arenicola L.B. Sm.

\section{CR, Bla}

Publicación: Phytologia 16(2): 77, t. 1, f. 19, 20. 1968.

Colección tipo: N. Angulo 1254

Henbarios: US; HUT.

Nombre común: Achupaya.

Registro departamental: LL.

Regiones Ecológicas: D ST; altitud desconocida.

SINAN PE: Sin registro.

Herbarios peruanos: HUT (isotipo citado).

Observaciones: Especie terrestre conocida sólo de una localidad cercana a la ciudad de Trujillo, donde no ha vuelto a ser recolectada desde 1949. La localidad original se halla en una de las zonas más importantes para la agricultura de caña de azúcar. Probablemente la expansión urbana y agrícola hayan destruido la localidad original.

\section{Tillandsia aurea Mez aurea}

\author{
Publicación: \\ Colección tipo: A. Weberbauer 3297 \\ Herbarios: B. \\ Nombre común: D esconocido. \\ Registro departamental: AN. \\ Regiones Ecológicas: MA; 2600-2700 m. \\ SINANPE: Sin registro. \\ Herbarios peruanos: Ninguno.
}

Observaciones: Este taxón fue considerado por Brako \& Zarucchi (1993) como un endemismo; sin embargo, no ha sido posible evaluarlo, ni asignarle una categoría.

\section{Tillandsia aurea Mez minorL. H rom. \& Rauh}

$$
\text { EN, Bla }
$$

Publicación: Trop. Subtrop. Pflanzenwelt 52(16): 66, f. 40. 1985.

Colección tipo: H. Hromadnik \& L. Hromadnik 4206

Herbarios: HEID, WU.

Nombre común: D esconocido.

Registro departamental: AM, CA.

Regiones Ecológicas: BS; $1150-1700 \mathrm{~m}$.

SINANPE: Sin registro.

Herbarios peruanos: Ninguno.

Observaciones: Taxón registrado por Brako \& Zarucchi (1993) como de Ancash, pero corresponde a Amazonas. Esta variedad se conoce solamente de la cuenca del río Marañón, donde, al parecer, no ha vuelto a ser recolectada desde 1978.

\section{Tillandsia baguagrandensis Rauh}

DD

Publicación: J. Bromeliad Soc. 37(6): 259-260 1987.

Colección tipo: U. Perino s.n.

Herbarios: HEID, WU.

Nombre común: Desconocido.

Registro departamental: AM.

Regiones Ecológicas: BS; $800 \mathrm{~m}$.

SINAN PE: Sin registro.

Herbarios peruanos: Ninguno. 
O bservaciones: Esta especie fue citada erróneamente en el protólogo como procedente de Apuŕmac, pero en realidad fue recolectada en Amazonas, valle del Marañón. Se desconoceel estado desus poblaciones.

\section{Tillandsia balsasensis Rauh}

Publicación: Trop. Subtrop. Pflanzenwelt 18(6): 5-8. 1976.

Colección tipo: W. Rauh 38570

Herbarios: HEID, US.

Nombre común: D esconocido.

Registro departamental: AM.

Regiones Ecológicas: BS; $1700 \mathrm{~m}$.

SINANPE: Sin registro.

Herbarios peruanos: Ninguno.

Observaciones: Esta especie es propia de la cuenca del Marañón. La localidad original está ubicada en Amazonas y no en Cajamarca, como inicialmente fue registrada. No ha sido posible evaluarla, ni asignarle una categoría.

\section{Tillandsia bismarckii Rauh \& Lehmann}

Publicación: Trop. Subtrop. Pflanzenwelt 41(12): 22, f. 10. 1983.

Colección tipo: W. Rauh \& K. von Bismarck 53653

Herbarios: HEID.

Nombre común: D esconocido.

Registro departamental: SM.

Regiones Ecológicas: BMHP; $1000 \mathrm{~m}$.

SINANPE: Sin registro.

Hembarios peruanos: Ninguno.

Observaciones: Este taxón fue considerado por Brako \& Zarucchi (1993) como un endemismo; sin embargo, no ha sido posible evaluarlo, ni asignarle una categoría.

\section{Tillandsia brevilingua Mez ex Harms}

Publicación: Engl. \& Prantl, Nat. Pflanzenfam., ed. 2, 15a:132. 1930.

Colección tipo: E.H.G. Ule 61- P

Herbarios: B.

Nombre común: D esconocido.

Registro departamental: LO.

Regiones Ecológicas: BMHP; altitud desconocida.

SINANPE: Sin registro.

Hemarios peruanos: Ninguno.

Observaciones: Este taxón fue considerado por Brako \& Zarucchi (1993) como un endemismo; sin embargo, no ha sido posible evaluarlo, ni asignarle una categoría.

159. Tillandsia cacticola L.B. Sm.

$$
\text { VU, Bla }
$$

Publicación: Contr. U.S. Natl. Herb. 29(11): 534, f. 89. 1954.

Colección tipo: C. Sandeman 4325

Hembarios: $\mathrm{K}$.

Nombre común: Achupaya, chayape, siempre viva, sogo tuyo

Registro departamental: $\mathrm{AM}, \mathrm{CA}, \mathrm{HU}$, LA, LL, PI.

Regiones Ecológicas: MDE, MA; 325$2600 \mathrm{~m}$.

SINAN PE: Sin registro.
Henbarios penuanos: CPUN (2), HAO (2), HUT (3), USM (8).

Observaciones: Esta especie se conoce de varios ejemplares recolectados en diversas partes de los Andes peruanos; en todos los casos parece ser poco común. O cupa laderas rocosas con vegetación xérica en valles interandinos. Escasa por tala de cactáceas y árboles.

\section{Tillandsia cajamarcensis Rauh}

Publicación: Trop. Subtrop. Pflanzenwelt 52(16):43-44, f. 26. 1985.

Colección tipo: W. Rauh 24305a

Herbarios: HEID.

Nombre común: D esconocido.

Registro departamental: CA.

Regiones Ecológicas: MA; $2800 \mathrm{~m}$.

SINAN PE: Sin registro.

Herbarios peruanos: Ninguno.

Observaciones: Este taxón fue considerado por Brako \& Zarucchi (1993) como un endemismo; sin embargo, no ha sido posible evaluarlo, ni asignarle una categoría.

\section{Tillandsia carnosa L.B. Sm. brevistipitata Rauh}

\author{
Publicación: Fl. Neotrop. 14(2): 904. 1977. \\ Colección tipo: W. Rauh 24568 \\ Hemarios: HEID, US. \\ Nombre común: D esconocido. \\ Registro departamental: AM. \\ Regiones Ecológicas: BMHM; $1200 \mathrm{~m}$. \\ SINAN PE: Sin registro. \\ Hembarios peruanos: Ninguno.
}

Observaciones: Este taxón fue considerado por Brako \& Zarucchi (1993) como un endemismo; sin embargo, no ha sido posible evaluarlo, ni asignarle una categoría.

\section{Tillandsia carnosa L.B. Sm. longispicata Rauh}

\author{
Publicación: Fl. Neotrop. 14(2):904. 1977. \\ Colección tipo: W. Rauh 14418 \\ Hemarios: HEID, US. \\ Nombre común: D esconocido. \\ Registro departamental: AM. \\ Regiones Ecológicas: BS; $500 \mathrm{~m}$. \\ SINAN PE: Sin registro. \\ Herbarios peruanos: Ninguno.
}

Observaciones: Este taxón fue considerado por Brako \& Zarucchi (1993) como un endemismo; sin embargo, no ha sido posible evaluarlo, ni asignarle una categoría.

\section{Tillandsia cereicola Mez}

\section{NT}

Publicación: Repert. Spec. Nov. Regni Veg. 3: 34-35. 1906.

Colección tipo: A. Weberbauer 3025

Hemanios: B.

Nombre común: D esconocido.

Registro departamental: AM, AN, CA, LL. Regiones Ecológicas: MA; 1000-2200 m. SINAN PE: Sin registro.

Herbarios penuanos: CPUN (1), HUT (9). 
Observaciones: Esta especie se conoce de varias localidades en el norte del país, tanto en la vertiente occidental, por ejemplo en la cuenca del río Santa, como en la oriental en la cuenca del río Marañón. Crece tanto en laderas rocosas o como una epífita en matorrales con árboles dispersos.

\section{Tillandsia cerrateana L.B.Sm.}

$$
\text { VU, Bla }
$$

Publicación: Phytologia 5(8): 398-399, t. 1, f. 9, 101956.

Colección tipo: E. Cerrate 391

Herbarios: US; USM!.

Nombre común: D esconocido.

Registro departamental: AN, CA, CU.

Regiones Ecológicas: MA, PSH; 3560 m. SINAN PE: PNH

Herbarios peruanos: HUT (1), USM (isotipo +2$)$.

Observaciones: Hierba epipétrica conocida de poblaciones naturalmente fragmentadas, en valles interandinos. Una sola población recibe protección oficial; sin embargo esto no prevé que incendios intencionales sean una amenaza para esta especie.

\section{Tillandsia chiletensis Rauh}

\section{CR, Bla}

Publicación: Trop. Subtrop. Pflanzenwelt 50(15):5-6, f. 1. 1984.

Colección tipo: W. Rauh 24256a

Herbarios: HEID.

Nombre común: D esconocido.

Registro departamental: CA.

Regiones Ecológicas: MA; 2000 m.

SINAN PE: Sin registro.

Hembarios peruanos: Ninguno.

Obsenvaciones: Hierba epífita conocida, aparentemente, sólo de la colección tipo, procedente del valle de Cajamarca. Amenazas a sus poblaciones estarín asociadas a incendios de matormales y bosques.

\section{Tillandsia chuninensis Rauh}

Publicación: Trop. Subtrop. Pflanzenwelt 53(17):39, f. 21. 1985.

Colección tipo: K. von Bismarck 32682

Herbarios: HEID.

Nombre común: D esconocido.

Registro departamental: LI.

Regiones Ecológicas: MDE; $1700 \mathrm{~m}$.

SINANPE: Sin registro.

Herbarios peruanos: Ninguno.

Observaciones: Este taxón fue considerado por Brako \& Zarucchi (1993) como un endemismo; sin embargo, no ha sido posible evaluarlo, ni asignarle una categoría.

\section{Tillandsia clavigera Rauh pendula Rauh}

\section{CR, Bla}

Publicación: Trop. Subtrop. Pflanzenwelt 52(16):59, f. 36. 1985.

Colección tipo: W. Rauh 63924

Herbarios: HEID.

Nombre común: D esconocido.

Registro departamental: PA.

Regiones Ecológicas: BMHM; $2400 \mathrm{~m}$.

SINAN PE: Sin registro.

Herbarios peruanos: Ninguno.
Observaciones: Taxón conocido sólo del material tipo, una planta recolectada en la cuenca del Paucartambo, cerca al límite con Junín. La localidad tipo se ubica en una zona de alta tasa de deforestación.

\section{Tillandsia coinaensis E hlers}

Publicación: Bromelie 1990(1):9. 1990.

Colección tipo: E.P. Ehlers 7873

Herbarios: WU.

Nombre común: D esconocido.

Registro departamental: LL.

Regiones Ecológicas: MA; altitud desconocida.

SINAN PE: Sin registro.

Henbarios peruanos: Ninguno.

Observaciones: Este taxón fue considerado por Brako \& Zarucchi (1993) como un endemismo; sin embargo, no ha sido posible evaluarlo, ni asignarle una categoría.

\section{Tillandsia commixa Mez}

Publicación: Repert. Spec. Nov. Regni Veg. 16(448-455):75. 1919.

Colección tipo: A. Mathews s.n.

Herbarios: $\mathrm{K}$.

Nombre común: D esconocido.

Registro departamental: AM.

Regiones Ecológicas: BMHM; altitud desconocida.

SINANPE: Sin registro.

Hembarios peruanos: Ninguno.

Observaciones: Este taxón fue considerado por Brako \& Zarucchi (1993) como un endemismo; sin embargo, no ha sido posible evaluarlo, ni asignarle una categoría.

\section{Tillandsia denudata Rauh vivipara Rauh}

\section{DD}

Publicación: Trop. Subtrop. Pflanzenwelt 52(16):63-64, f. 38.. 1985.

Colección tipo: W. Rauh 40030

Hemarios: HEID.

Nombre común: D esconocido.

Registro departamental: AM.

Regiones Ecológicas: MA; 2700 m.

SINAN PE: Sin registro.

Herbarios peruanos: Ninguno.

Observaciones: Esta variedad se conoce dela cuenca del Marañón, de localidad exacta desconocida. La variedad típica crece de Colombia al Perú. Se desconoce el estado de sus poblaciones.

171. Tillandsia diffusa L.B. Sm.

\section{EN, Bla}

Publicación: Phytologia 9(4): 252-253, t. 3, f. 9, 10. 1963.

Colección tipo: J.J. Wurdack 1547

Herbarios: US.

Nombre común: D esconocido.

Registro departamental: AM, AN, CA.

Regiones Ecológicas: BS; $1700-2600$ m. SINAN PE: Sin registro.

Hembarios penuanos: CPUN (2), HAO (1), HUT (2). 
Observaciones: Hierba epífita de ambientes semixéricos, en la cuenca del Marañón. Poblaciones de esta especie han sido registradas en varias oportunidades y en diferentes años. No se conoce de amenazas precisas a esta especie.

172. Tillandsia ecaninata L.B. Sm.

\section{DD}

Publicación: Phytologia 20(3): 162, t. 1, f. 1-3. 1970.

Colección tipo: W. Rauh RP-20390

Herbarios: US.

Nombre común: D esconocido.

Registro departamental: AM, PI.

Regiones Ecológicas: BS; 300-700 m.

SINANPE: Sin registro.

Hembarios penuanos: HUT (1), USM (1).

Observaciones: Hierba conocida de las cuencas del Marañón y Huancabamba, donde, al parecer, no ha vuelto a ser recolectada desde 1982. Se desconoce el estado de sus poblaciones.

\section{Tillandsia elvirae-grossiae Rauh}

Publicación: Trop. Subtrop. Pflanzenwelt 65:49, f. 30-33. 1988.

Colección tipo: W. Rauh 38332

Hemarios: HEID.

Nombre común: D esconocido.

Registro departamental: AM.

Regiones Ecológicas: BMHP; $1400 \mathrm{~m}$.

SINANPE: Sin registro.

Herbarios peruanos: Ninguno.

Observaciones: Este taxón fue considerado por Brako \& Zarucchi (1993) como un endemismo; sin embargo, no ha sido posible evaluarlo, ni asignarle una categoría.

\section{Tillandsia extensa Mez}

\section{DD}

Publicación: Repert. Spec. Nov. Regni Veg. 3: 33-34. 1906.

Colección tipo: A. Weberbauer 3296

Herbarios: B; MOL!

Nombre común: D esconocido.

Registro departamental: AN, LA.

Regiones Ecológicas: MA; $2500 \mathrm{~m}$.

SINAN PE: Sin registro.

Herbarios penuanos: MOL (isotipo).

Observaciones: Hierba terrestre recolectada en dos localidades en el norte del país. El ejemplar tipo proviene del Callejón de Conchucos. Se desconoce el estado de sus poblaciones.

\section{Tillandsia gerd-muelleri W. Weber}

\section{DD}

Publicación: Feddes Repert. 94: 611. 1983.

Colección tipo: G. Müller \& P. G utte 9441

Herbarios: LZ.

Nombre común: D esconocido.

Registro departamental: CU.

Regiones Ecológicas: Sin datos; altitud desconocida.

SINAN PE: Sin registro.

Herbarios peruanos: Ninguno.
Observaciones: Esta especie herbácea es conocida aparentemente sólo de la colección tipo, una planta de procedencia exacta desconocida.

\section{Tillandsia gutteana W. Weber}

Publicación: Feddes Repert. 94: 613. 1983.

Colección tipo: P. Gutte \& G. Gutte 3948

Herbarios: LZ

Nombre común: D esconocido.

Registro departamental: CA.

Regiones Ecológicas: Sin datos; altitud desconocida.

SINAN PE: Sin registro.

Herbarios peruanos: Ninguno.

Observaciones: Hierba conocida aparentemente sólo de la colección tipo. No ha sido posible evaluarla, ni asignarle una categonía.

\section{Tillandsia heteromorpha Mez}

$$
\text { EN, Bla }
$$

Publicación: Repert. Spec. Nov. Regni Veg. 3: 41-42. 1906.

Colección tipo: A. Weberbauer 3742

Henbarios: $\mathrm{B}$.

Nombre común: D esconocido.

Registro departamental: AN, CA, LA, LL.

Regiones Ecológicas: MA; 850- 3400 m.

SINANPE: Sin registro.

Hemarios peruanos: HUT (2).

Observaciones: Esta especie péndula fue descrita de un ejemplar proveniente de la cuenca del nó Puccha. Rauh (1990) señala que habita ambientes xéricos, en valles interandinos y fragmentos de bosque seco.

\section{Tillandsia hildae Rauh}

Publicación: Trop. Subtrop. Pflanzenwelt 3(1): 185-195 1973.

Colección tipo: W. Rauh 24329

Herbarios: HEID, US.

Nombre común: D esconocido.

Registro departamental: CA.

Regiones Ecológicas: BS; $1000 \mathrm{~m}$.

SINAN PE: Sin registro.

Herbarios peruanos: USM (2).

Observaciones: Este taxón fue considerado por Brako \& Zarucchi (1993) como un endemismo; sin embargo, no ha sido posible evaluarlo, ni asignarle una categoría.

\section{Tillandsia huarazensis Ehlers \& W. Till}

Publicación: Bromelie 1988(2): 21. 1988.

Colección tipo: K. Kinze s.n.

Herbarios: WU.

Nombre común: D esconocido.

Registro departamental: AN.

Regiones Ecológicas: PSH; altitud desconocida.

SINANPE: Sin registro.

Herbarios peruanos: Ninguno.

Observaciones: Este taxón fue considerado por Brako \& Zarucchi (1993) como un endemismo; sin embargo, no ha sido posible evaluarlo, ni asignarle una categoría. 


\section{Tillandsia intermupta $\mathrm{Mez}$}

DD

Publicación: Repert. Spec. Nov. Regni Veg. 3: 38. 1906.

Colección tipo: A. Weberbauer 2736 p.p.

Herbarios: B.

Nombre común: Desconocido.

Registro departamental: AN, LI.

Regiones Ecológicas: MA; 2400-2900 m.

SINAN PE: Sin registro.

Herbarios peruanos: Ninguno.

Observaciones: Hierba epífita conocida de dos localidades en la vertiente del Pacífico. El ejemplar tipo crecía sobre A lnus aauminata. Se desconoce el estado de sus poblaciones.

\section{Tillandsia kauffmannii Ehlers}

Publicación: Trop. Subtrop. Pflanzenwelt 75: 32, t 17. 1990.

Colección tipo: E.P. Ehlers \& K. Ehlers P 78105

Herbarios: WU.

Nombre común: D esconocido.

Registro departamental: LL.

Regiones Ecológicas: MA; altitud desconocida.

SINANPE: Sin registro.

Herbarios peruanos: Ninguno.

Observaciones: Este taxón fue considerado por Brako \& Zarucchi (1993) como un endemismo; sin embargo, no ha sido posible evaluarlo, ni asignarle una categoría

\section{Tillandsia kirschnekii Rauh \& W. Till}

DD

Publicación: Trop. Subtrop. Pflanzenwelt 43(14): 79. 1983.

Colección tipo: Kirschnek 39770

Hemarios: HEID.

Nombre común: D esconocido.

Registro departamental: AP.

Regiones Ecológicas: Sin datos; altitud desconocida.

SINAN PE: Sin registro.

Herbarios peruanos: Ninguno.

Observaciones: Hierba descrita de una planta cultivada, probablemente recolectada en el departamento de Apurímac.

\section{Tillandsia koideae Rauh \& E. Gross}

Publicación: Trop. Subtrop. Pflanzenwelt 79: 19, t. 9. 1991.

Colección tipo: P. Koide s.n.

Herbarios: HEID.

Nombre común: D esconocido.

Registro departamental: PI.

Regiones Ecológicas: MA; $2800 \mathrm{~m}$.

SINAN PE: Sin registro.

Herbarios peruanos: Ninguno.

Observaciones: Este taxón fue considerado por Brako \& Zarucchi (1993) como un endemismo; sin embargo, no ha sido posible evaluarlo, ni asignarle una categoría.

\section{Tillandsia krahnii Rauh}

Publicación: Trop. Subtrop. Pflanzenwelt 33(10): 9-11,107. 1981.

Colección tipo: W. Krahn 595

Herbarios: HEID.

Nombre común: D esconocido.

Registro departamental: AN.

Regiones Ecológicas: Sin datos; altitud desconocida.

SINAN PE: Sin registro.

Herbarios peruanos: Ninguno.

Observaciones: Estetaxón fue considerado por Brako \& Zarucchi (1993) como un endemismo; sin embargo, no ha sido posible evaluarlo, ni asignarle una categoría.

\section{Tillandsia knukoffiana L.B. Sm. piepenbringii} Rauh

Publicación: J. Bromeliad Soc. 36: 259. 1986.

Colección tipo: W. Rauh 35343

Herbarios: HEID.

Nombre común: D esconocido.

Registro departamental: CA.

Regiones Ecológicas: Sin datos; altitud desconocida.

SINANPE: Sin registro.

Herbarios peruanos: Ninguno.

Observaciones: Variedad conocida solamente del ejemplar tipo. No ha sido posible evaluarla, ni asignarle una categoría.

186. Tillandsia landbeckii Phill. subsp. andina W. Till

Publicación: Bromelie 1991(3): 71- 73. 1992. Colección tipo: W. Till \& E. Vitek 169

Herbarios: K, SEL, WU; USM.

Nombre común: D esconocido.

Registro departamental: AY, CU.

Regiones Ecológicas: MA; 2900-3200 m.

SINAN PE: Sin registro.

Hembarios penuanos: USM (isotipo citado).

Observaciones: Este taxón fue considerado por Brako \& Zarucchi (1993) como un endemismo; sin embargo, no ha sido posible evaluarlo, ni asignarle una categoría.

\section{Tillandsia latifolia G. Meyen leucophylla Rauh}

Publicación: Trop. Subtrop. Pflanzenwelt 13(4): 21-26. 1974.

Colección tipo: W. Rauh 35340

Hemarios: HEID.

Nombre común: D esconocido.

Registro departamental: LI.

Regiones Ecológicas: Sin datos; altitud desconocida.

SINANPE: Sin registro.

Herbarios peruanos: Ninguno.

Observaciones: Las variedades no han sido reconocidas en la mayoría de los ejemplares de los herbarios peruanos. No ha sido posible evaluarla, ni asignarle una categoría. 
188. Tillandsia latifolia G. Meyen majorMez

Publicación: Monogr. Phan. 9: 790. 1896.

Colección tipo: A. Gaudichaud 64

Herbarios: B.

Nombre común: D esconocido.

Registro departamental: CA.

Regiones Ecológicas: Sin datos; altitud desconocida.

SINANPE: Sin registro.

Hemarios peruanos: Ninguno.

Observaciones: Las variedades no han sido reconocidas en la mayoría de los ejemplares de los herbarios peruanos. No ha sido posible evaluarla, ni asignarle una categoría.

\section{Tillandsia laxissima moorei $\mathrm{H}$. Luther}

Publicación: Selbyana 20(1): 13. 1999.

Colección tipo: L. Moore s.n.

Herbarios: SEL.

Nombre común: D esconocido.

Registro departamental: SM.

Regiones Ecológicas: BMHM; altitud desconocida.

SINAN PE: Sin registro.

Hemarios peruanos: Ninguno.

Observaciones: Este taxón fue descrito posterior a Brako \& Zarucchi (1993); no ha sido posible evaluarlo, ni asignarle una categonía.

\section{Tillandsia lindeni Regel lindeni}

\author{
Publicación: \\ Colección tipo: G. Wallis s.n. \\ Herbarios: \\ Nombre común: D esconocido. \\ Registro departamental: PI. \\ Regiones Ecológicas: MA; $1250 \mathrm{~m}$. \\ SINAN PE: Sin registro. \\ Hemarios peruanos: Ninguno.
}

Observaciones: Este taxón fue considerado por Brako \& Zarucchi (1993) como un endemismo; sin embargo, no ha sido posible evaluarlo, ni asignarle una categoría.

191. Tillandsia lopezii L.B. Sm.

$$
\text { EN, Bla }
$$

Publicación: Phytologia 8(9): 502-503, t. 2, f. 15, 16. 1963

Colección tipo: A. López M. 1750

Herbarios: US; HUT!

Nombre común: Desconocido,

Registro departamental: AN, LL.

Regiones Ecológicas: MA, PAR; 3300$3800 \mathrm{~m}$.

SINANPE: PNH

Herbarios peruanos: HUT (isotipo+1).

Observaciones: Esta especie se conoce de las cuencas de los ríos Santa y Marañón, donde ocupa laderas rocosas; al parecer, no ha vuelto a ser recolectada desde 1970 . Incendios intencionales podría afectarla.
192. Tillandsia macbrideana L.B. Sm.

$$
\text { VU, Bla }
$$

Publicación: Contr. Gray Herb. 89: 11, t. 2, f. 1-3. 1930.

Colección tipo: J.F. Macbride \& W. Featherstone 2258

Herbarios: $F, \mathrm{GH}$

Nombre común: D esconocido.

Registro departamental: AM, CA, HU, LL, LI.

Regiones Ecológicas: MA, PAR; 2100$3250 \mathrm{~m}$.

SINANPE: Sin registro.

Herbarios peruanos: CPUN (2).

Observaciones: Hierba terrestre o epipétrica conocida de varias localidades fragmentadas, en el norte del Perú, donde crece en sitios rocosos. Cinco variedades han sido reconocidas en esta especie, todas ellas endémicas; sin embargo pocas están reconocida en el material de herbario consultado.

193. Tillandsia micans L.B.Sm.

$$
\text { CR, Bla }
$$

Publicación: Phytologia 5(9): 402, t. 1, f. 8-10. 1956.

Colección tipo: R. Ferreyra 9879

Hemarios: US; USM!

Nombre común: Huaccontuy.

Registro departamental: CU.

Regiones Ecológicas: MA; 3100 m.

SINANPE: Sin registro.

Herbarios peruanos: USM (isotipo)

Observaciones: Esta especie se conoce, al parecer, de una localidad en el valle del Urubamba, donde no ha vuelto a ser recolectada desde 1954. Por su hábitat, amenazas potenciales provienen de los incendios intencionales.

\section{Tillandsia mima L.B. Sm. chiletensis Rauh}

Publicación: Trop. Subtrop. Pflanzenwelt 21(7): 21-28. 1977

Colección tipo: W. Rauh 40007

Hembarios: HEID.

Nombre común: D esconocido.

Registro departamental: CA.

Regiones Ecológicas: Sin datos; altitud desconocida.

SINAN PE: Sin registro.

Herbarios peruanos: Ninguno.

Observaciones: Este taxón fue considerado por Brako \& Zarucchi (1993) como un endemismo; sin embargo, no ha sido posible evaluarlo, ni asignarle una categoría.

\section{Tillandsia onoyensis Mez secundiflora Rauh}

Publicación: Trop. Subtrop. Pflanzenwelt 21(7): 19, f. 9. 1977

Colección tipo: W. Rauh 40402

Herbarios:

Nombre común: D esconocido.

Registro departamental: AN.

Regiones Ecológicas: Sin datos; altitud desconocida.

SINAN PE: Sin registro.

Herbarios peruanos: Ninguno. 
Observaciones: Este taxón fue considerado por Brako \& Zarucchi (1993) como un endemismo; sin embargo, no ha sido posible evaluarlo, ni asignarle una categoría.

\section{Tillandsia oxapampae Rauh \& von Bismanck} DD

Publicación: Trop. Subtrop. Pflanzenwelt 53(17): 20, f. 9. 1985.

Colección tipo: W. Rauh \& K. von Bismarck 66069

Herbarios: HEID.

Nombre común: D esconocido.

Registro departamental: PA

Regiones Ecológicas: BMHM; $1900 \mathrm{~m}$.

SINANPE: Sin registro.

Herbarios peruanos: Ninguno.

Observaciones: Esta especie se conoce, al parecer, sólo de la colección tipo, la cual fue recolectada en 1984, en un fragmento de bosque con Juglans neotropica, bordeando campos agrícolas. Se desconoce el estado de sus poblaciones.

\section{Tillandsia paleaceaC. Presl subsp. apunimacensisW. Till}

Publicación: J. Bromeliad Soc. 43: 7-10. 1993.

Colección tipo: W. Till 183

Herbarios: WU; USM.

Nombre común: Desconocido.

Registro departamental: AP.

Regiones Ecológicas: MA; altitud desconocida.

SINANPE: Sin registro.

Herbarios penuanos: USM (isotipo citado).

Observaciones: Este taxón fue considerado por Brako \& Zarucchi (1993) como un endemismo; sin embargo, no ha sido posible evaluarlo, ni asignarle una categoría.

\section{Tillandsia penuviana J.R. Grant}

Publicación: Phytologia 75(2): 173. 1993. Colección tipo: A. López M. \& A. Sagástegui A. 5175

Herbarios: HEID ; HUT.

Nombre común: D esconocido.

Registro departamental: CA

Regiones Ecológicas: MA; altitud desconocida.

SINAN PE: Sin registro

Herbarios peruanos: HUT (isotipo citado).

Observaciones: Este taxón fue considerado por Brako \& Zarucchi (1993) como un endemismo; sin embargo, no ha sido posible evaluarlo, ni asignarle una categoría.

\section{Tillandsia pinnato-digitata Mez}

Publicación: Repert. Spec. Nov. Regni Veg. 3: 39. 1906.

Colección tipo: A. Weberbauer 2736

Herbarios: B.

Nombre común: D esconocido.

Registro departamental: AN.

Regiones Ecológicas: MA; 2400-2900 m.

SINAN PE: Sin registro.

Herbarios peruanos: Ninguno.
Observaciones: Este taxón fue considerado por Brako \& Zarucchi (1993) como un endemismo; sin embargo, no ha sido posible evaluarlo, ni asignarle una categoría.

200. Tillandsia piurensis L.B. Sm.

\section{DD}

Publicación: Phytologia 13(2): 146. 1966. Colección tipo: P.C. Hutchison \& J.K. Wright 6616

Herbanios: UC, US; USM!.

Nombre común: D esconocido.

Registro departamental: PI.

Regiones Ecológicas: MA; 1900 m.

SINANPE: Sin registro.

Herbarios peruanos: USM (isotipo).

Observaciones: Hierba conocida sólo de la cuenca del Huancabamba, de laderas rocosas y pronunciadas. Al parecer, no ha vuelto a ser recolectada desde 1964

\section{Tillandsia platyphylla Mez}

\section{DD}

Publicación: Repert. Spec. Nov. Regni Veg. 3: 37. 1906.

Colección tipo: A. Weberbauer 3888

Herbarios: $\mathrm{B}$.

Nombre común: D esconocido.

Registro departamental: CA.

Regiones Ecológicas: BS; $800 \mathrm{~m}$.

SINAN PE: Sin registro.

Herbarios peruanos: Ninguno.

Observaciones: Esta especie se conoce solamente de la cuenca del río Utcubamba. No ha vuelto a ser recolectada desde 1970.

\section{Tillandsia platyrhachis Mez magnifica Rauh \& von Bismarck}

Publicación: Trop. Subtrop. Pflanzenwelt 53(17): 9-11, f. 3, 4, 4a. 1985.

Colección tipo: W. Rauh \& K. von

Bismarck 66107

Herbarios: HEID.

Nombre común: D esconocido.

Registro departamental: HU.

Regiones Ecológicas: BMHM; 1900 m.

SINAN PE: Sin registro.

Herbarios peruanos: Ninguno.

Observaciones: Este taxón se conoce sólo del material tipo. No ha sido posible evaluarlo, ni asignarle una categoría.

\section{Tillandsia pomacochae Rauh}

Publicación: Trop. Subtrop. Pflanzenwelt 3(3): 25, f. 14-15. 1973.

Colección tipo: W. Rauh 24554

Hembarios: US.

Nombre común: D esconocido.

Registro departamental: AM.

Regiones Ecológicas: MA; 2100 m.

SINANPE: Sin registro.

Herbarios peruanos: Ninguno. 
Observaciones: Este taxón fue considerado por Brako \& Zarucchi (1993) como un endemismo; sin embargo, no ha sido posible evaluarlo, ni asignarle una categoría.

\section{Tillandsia propagulifera Rauh}

\section{DD}

Publicación: Trop. Subtrop. Pflanzenwelt 3(3): 10, f. 4-6. 1973.

Colección tipo: W. Rauh 24346

Herbarios: HEID.

Nombre común: D esconocido.

Registro departamental: AM, CA.

Regiones Ecológicas: BS; 1300-1400 m.

SINAN PE: Sin registro.

Herbarios peruanos: USM (2).

Observaciones: Especie descrita de una planta cuyos datos de procedencia, al igual que otras recolectadas por Rauh, son confusos. El ejemplar tipo, al parecer, fue recolectado en la cuenca del Utcubamba, río que discurre en el departamento de Amazonas, pero que erróneamente atribuyó a La Libertad.

\section{Tillandsia pseudomacbrideana Rauh}

\section{DD}

Publicación: Trop. Subtrop. Pflanzenwelt 53(17): 26, f. 12. 1985.

Colección tipo: W. Rauh 53774

Henbarios: HEID.

Nombre común: D esconocido.

Registro departamental: LL.

Regiones Ecológicas: MA; 2700 m.

SINAN PE: Sin registro.

Herbarios peruanos: Ninguno.

Observaciones: Especie conocida sólo de una localidad. Aparentemente no ha vuelto a ser recolectada desde 1980.

\section{Tillandsia pseudomicans Rauh}

\section{NE}

Publicación: Trop. Subtrop. Pflanzenwelt 12(3): 21-27. 1974.

Colección tipo: W. Rauh 25945

Hemarios: HEID.

Nombre común: D esconocido.

Registro departamental: AP.

Regiones Ecológicas: Sin datos; altitud desconocida.

SINAN PE: Sin registro.

Herbarios peruanos: Ninguno.

Observaciones: Hierba epífita, cuya procedencia requiere aclararse si es de Apurímac o de Cajamarca. No ha sido posible categorizarla.

\section{Tillandsia pucaraensis E hlers}

Publicación: Bromelie 1989(1): 9. 1989.

Colección tipo: E.P. Ehlers P7953

Herbarios: WU.

Nombre común: D esconocido.

Registro departamental: CA.

Regiones Ecológicas: MDE, BS; 1200 m.

SINAN PE: Sin registro.

Hemarios peruanos: Ninguno.

Observaciones: Esta especie se conoce dela cuencadel nío Chamaya, en una zona ecotonal de bosque- matorral. No ha sido posible evaluarla, ni asignarle una categoría.

\section{Tillandsia purpurascens E. Gross}

\section{DD}

Publicación: Trop. Subtrop. Pflanzenwelt 75: 34, t.18. 1990.

Colección tipo: W. Rauh 69427a

Herbarios: HEID.

Nombre común: D esconocido.

Registro departamental: PI.

Regiones Ecológicas: MA; $3000 \mathrm{~m}$.

SINAN PE: Sin registro.

Herbarios peruanos: Ninguno.

Observaciones: Esta especie epífita fue descrita de una planta recolectada en la cuenca del Huancabamba. Probablemente en cultivo. Se desconoce el estado de sus poblaciones.

209. Tillandsia rauhii L.B. Sm. rauhii

\section{DD}

Publicación:

Colección tipo: W. Rauh P-379

Herbarios: US.

Nombre común: D esconocido.

Registro departamental: LA.

Regiones Ecológicas: MDE; $700 \mathrm{~m}$.

SINAN PE: Sin registro.

Herbarios peruanos: Ninguno.

Observaciones: Este taxón herbáceo fue descrito de una planta, al parecer, recolectada en la cuenca del Saña. Se desconoce el estado de sus poblaciones.

\section{Tillandsia rauhii L.B. Sm. longispica Rauh}

\section{DD}

Publicación: Trop. Subtrop. Pflanzenwelt 75: 37, t. 19. 1990.

Colección tipo: W. Rauh 69431

Herbarios: HEID.

Nombre común: D esconocido.

Registro departamental: CA, LA, PI.

Regiones Ecológicas: BS; $700 \mathrm{~m}$.

SINAN PE: Sin registro.

Herbarios peruanos: Ninguno.

Observaciones: Hierba terrestre conocida de unas pocas localidades en el nor-occidente del país. El tipo proviene de la cuenca media del río Chancay. Se desconoce el estado de sus poblaciones.

211. Tillandsia reducta L.B. Sm.

\section{DD}

Publicación: Phytologia 5(8): 399, t. 1, f. 11, 12. 1956.

Colección tipo: R. Ferreyra 3216

Herbarios: US; USM!.

Nombre común: D esconocido.

Registro departamental: CA, LL.

Regiones Ecológicas: MDE, MA; 1700$2600 \mathrm{~m}$.

SINAN PE: Sin registro.

Herbarios peruanos: HUT (1), USM (isotipo+1).

Observaciones: Hierba terrestre conocida de dos localidades en la cuenca del Marañón. Se desconoce el estado de sus poblaciones. 


\section{Tillandsia spiraliflora Rauh}

$$
\text { EN, Blab(iii) }
$$

Publicación: Trop. Subtrop. Pflanzenwelt 18(6): 8-12. 1976.

Colección tipo: W. Rauh 38567

Hemarios: HEID, US.

Nombre común: D esconocido.

Registro departamental: AM, CA.

Regiones Ecológicas: MDE; $1200 \mathrm{~m}$.

SINAN PE: Sin registro.

Herbarios peruanos: CPUN (1).

Observaciones: Hierba conocida de la cuenca del Marañón, de dos localidades muy cercanas. Aparentemente no ha vuelto a ser recolectada desde 1976.

\section{Tillandsia subconcolorL.B.Sm.}

$$
\text { EN, Blab(iii) }
$$

Publicación: Phytologia 20(3): 171, t. 1, f. 10, 11. 1970.

Colección tipo: W. Rauh 20811

Herbarios: US.

Nombre común: D esconocido.

Registro departamental: $\mathrm{CU}, \mathrm{HU}$.

Regiones Ecológicas: BMHP; $1200 \mathrm{~m}$.

SINANPE: Sin registro.

Herbarios peruanos: Ninguno.

Observaciones: Hierba epífita, conocida de unas tres poblaciones, en el centro y sur-oriente del país. El ejemplar tipo y una recolecta adicional provienen de la cuenca del Urubamba, de una zona con abundante actividad agrícola.

\section{Tillandsia teres L.B. Sm.}

\section{EN, Bla}

Publicación: Phytologia 16(2): 78- 79, t. 1, f. 23, 24. 1968.

Colección tipo: A. López M. \& A Sagástegui A. 5541

Herbarios: $\underline{\mathrm{HUT}}$.

Nombre común: D esconocido.

Registro departamental: $\mathrm{CA}$.

Regiones Ecológicas: MD E; 750 - $800 \mathrm{~m}$

SINANPE: Sin registro.

Herbarios peruanos: HUT (holotipo citado+1).

Observaciones: Hierba terrestre conocida solamente de la cuenca alta del Chancay, en el norte de la vertiente del Pacífico. Aparentemente,no ha vuelto a ser recolectada desde 1965.

\section{Tillandsia truxillana L.B. Sm.}

\section{CR, Blab(iii)}

Publicación: Phytologia 8(9): 503-504, t. 3, f. 1, 2. 1963.

Colección tipo: A. López M. \& A. Sagástegui A. 3296

Herbarios: US.

Nombre común: D esconocido.

Registro departamental: LL.

Regiones Ecológicas: MA; 3000 m.

SINAN PE: Sin registro.

Herbarios peruanos: Ninguno.

Observaciones: Esta hierba terrestre es conocida solamente de la colección tipo, una planta proveniente de la cuenca del Marañón. A parentemente, no havuelto a ser recolectada desde 1960. La zona está afectada por la actividad minera.

\section{Tillandsia werdermannii $\mathrm{H}$ arms}

EN, B 1ab(iii)

Publicación: Notizbl. Bot. Gart. BerlinD ahlem 10: 218. 1928.

Colección tipo: E. Werdermann 717

Herbarios: B, MO.

Nombre común: D esconocido.

Registro departamental: MO, TA.

Regiones Ecológicas: D ST, MDE; 800$1200 \mathrm{~m}$.

SINAN PE: Sin registro.

Herbarios penuanos: HAO (1).

Observaciones: Esta hierba se conoce solamente de dos localidades, en el sur del país. Podría estar representada en la flora chilena.

\section{Tillandsia zaratensis W. Weber}

\section{CR, Blab(iii)}

Publicación: Feddes Repert. 94(9-10): 621. 1983.

Colección tipo: G. Müller \& P. G utte 9520

Herbarios: LZ.

Nombre común: Desconocido.

Registro departamental: LI.

Regiones Ecológicas: MA; altitud desconocida.

SINAN PE: Sin registro.

Hembarios peruanos: Ninguno.

Observaciones: Hierba conocida solamente de la localidad tipo, al este de la provincia de Lima. Aparentemente, proviene de uno de los fragmentos de bosque perennifolio, de la vertiente occidental. Este tipo de bosque está severamente afectado por la deforestación y el pastoreo intensivo.

\section{Vriesea curvispica Rauh}

\section{CR, Blab(iii)}

Publicación: Trop. Subtrop. Pflanzenwelt 42(13): 21-24, 53, f. 13. 1983.

Colección tipo: W. Rauh 52835

Herbarios: HEID.

Nombre común: D esconocido.

Registro departamental: AM.

Regiones Ecológicas: BS; $1200 \mathrm{~m}$.

SINAN PE: Sin registro.

Herbarios peruanos: Ninguno.

Observaciones: Esta planta saxícola se conoce de un ejemplar, recolectado en el valle del Marañón. Aparentemente, no ha vuelto a ser recolectada desde 1978.

\section{Vniesea ochracea Rauh \& E. Gross}

\section{DD}

Publicación: J. Bromeliad Soc. 34(5): 196-198. 1987.

Colección tipo: A. Lau s.n.

Herbarios: HEID.

Nombre común: D esconocido.

Registro departamental: PA.

Regiones Ecológicas: BMHM; $1800 \mathrm{~m}$.

SINAN PE: Sin registro.

Herbarios peruanos: Ninguno. 
Observaciones: Hierba epífita conocida solamente de la colección tipo, proveniente de material en cultivo. Se desconoce las características del hábitat de esta especie y la localidad exacta de su población.

\section{Vriesea oxapampae Rauh}

\section{DD}

Publicación: Trop. Subtrop. Pflanzenwelt 16(5): 22-25 1976.

Colección tipo: A. Lau s.n.

Herbarios: HEID.

Nombre común: D esconocido.

Registro departamental: PA.

Regiones Ecológicas: BMHM; altitud desconocida.

SINAN PE: Sin registro.

Herbarios peruanos: Ninguno.

Observaciones: Al igual que $\mathrm{V}$ riesea ochracea, poco se sabe de esta especie. Es conocida solamente de la colección tipo, una planta que se asume fue recolectada, probablemente, en la provincia de Oxapampa.

\section{Vriesea piepenbringii Rauh}

\section{EN, Bla}

Publicación: Trop. Subtrop. Pflanzenwelt 42(13): 12-21, f. 6, 7, 7a. 1983.

Colección tipo: W. Rauh 53548

Henbarios: HEID.

Nombre común: D esconocido.

Registro departamental: AM.

Regiones Ecológicas: BS; $1200 \mathrm{~m}$.

SINANPE: Sin registro.

Hembarios peruanos: Ninguno.

Observaciones: Hierba epífita conocida sólo de la cuenca del Utcubamba; al igual que otras especies descritas por Rauh, esta especie está en cultivo. Amenazas a sus poblaciones están asociadas a la deforestación.

\section{Vriesea subandina (Ule) L.B. Sm. \& Pittendrigh}

$$
\text { EN, Bla }
$$

Publicación: J. Wash. Acad. Sci. 43: 404. [1954] 1953.

Colección tipo: E.H.G. Ule 6684

Hemarios: $\mathrm{B}$.

Nombre común: D esconocido.

Registro departamental: AM, SM.

Regiones Ecológicas: BMHP; 900- 1200

m.

SINAN PE: Sin registro.

Herbarios peruanos: Ninguno.

Observaciones: Especie terrestre conocida de varias localidades dispersas, en las cuencas del Mayo e Imaza. La localidad original se atribuyó a Loreto (Brako \& Zarucchi, 1993), pero está oficialmente en San Martín.

\section{Vriesea tarmaensis Rauh}

\section{EN, Blab(iii)}

Publicación: Trop. Subtrop. Pflanzenwelt 43(14): 33-38, f. 19-20. 1983.

Colección tipo: W. Rauh 21147a

Hemarios: HEID.

Nombre común: D esconocido.

Registro departamental: JU, PA.

Regiones Ecológicas: BMHM; 1900$2700 \mathrm{~m}$.

SINANPE: Sin registro.

Herbarios peruanos: Ninguno.

Observaciones: Esta especie se conoce, al parecer, de dos localidades. La colección tipo, proviene de una localidad no especificada, que se ubica aquí en Junín, al mencionarse los bosques de Chanchamayo (como «Chanchomayotal»), donde al parecer, no ha vuelto a ser recolectada desde 1967. Los valles de Chanchamayo y de Oxapampa han sufrido fuertes pérdidas de sus ambientes boscosos debido a la expansión agrícola y rural. Grant (1995) ha considerado esta especie en el género W erauhia. 
Mapa del Perú indicando las abreviaturas de los departamentos

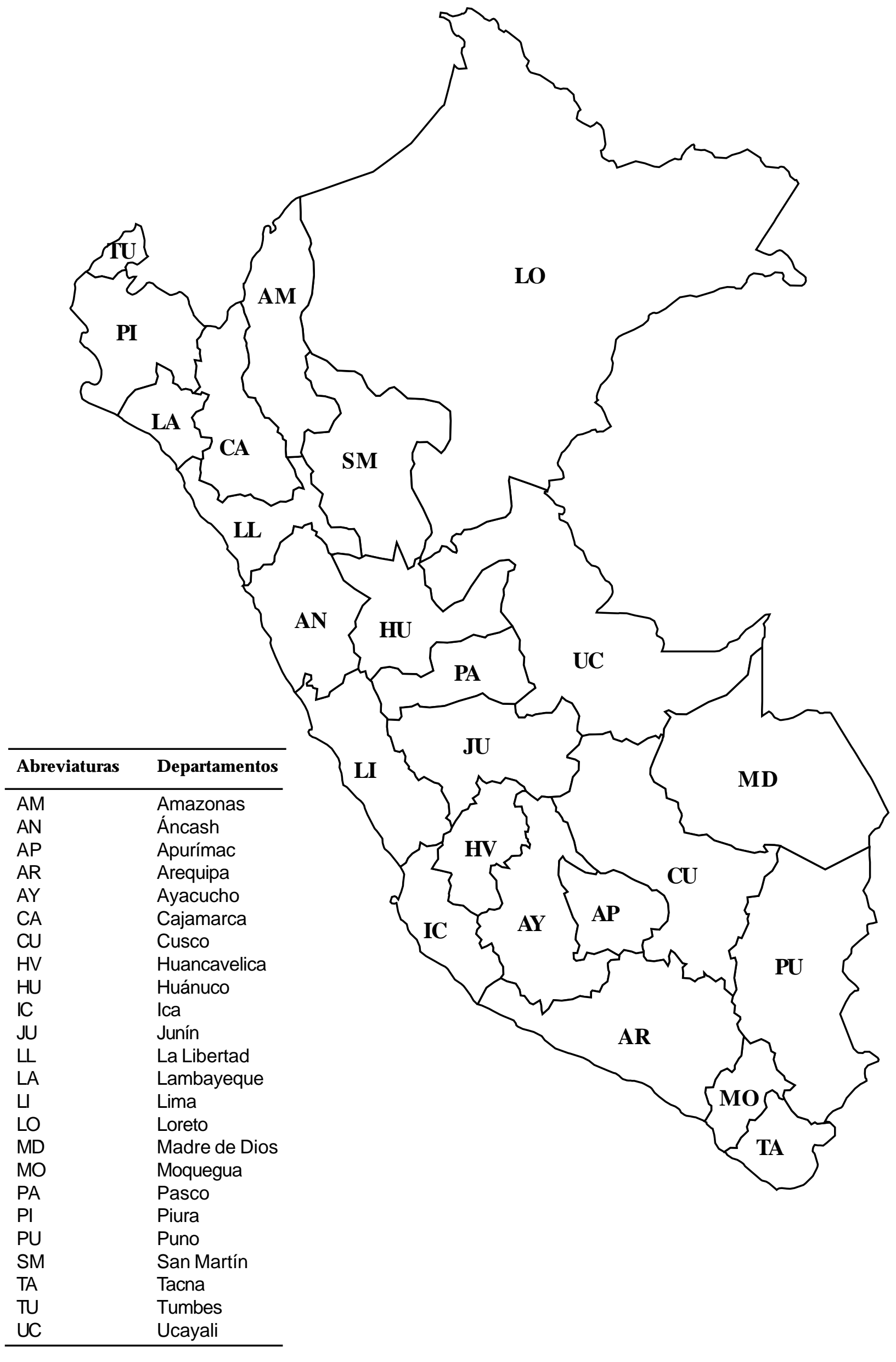

